\title{
Characterization and correction of OMPS nadir mapper measurements for ozone profile retrievals
}

\author{
Juseon Bak ${ }^{1, a}$, Xiong Liu ${ }^{2}$, Jae-Hwan Kim ${ }^{1}$, David P. Haffner ${ }^{3}$, Kelly Chance ${ }^{2}$, Kai Yang ${ }^{4}$, and Kang Sun ${ }^{2}$ \\ ${ }^{1}$ Department of Atmospheric Science, Pusan National University, Busan, Korea \\ ${ }^{2}$ Harvard-Smithsonian Center for Astrophysics, Atomic and Molecular Physics, Cambridge, MA, USA \\ ${ }^{3}$ Science Systems and Applications, Inc., 10210 Greenbelt Rd, Lanham, MD 20706, USA \\ ${ }^{4}$ Department of Atmospheric and Oceanic Science, University of Maryland College Park, College Park, Maryland, USA \\ ${ }^{\mathrm{a}}$ currently at: Harvard-Smithsonian Center for Astrophysics, Atomic and Molecular Physics, Cambridge, MA, USA
}

Correspondence to: Jae-Hwan Kim (jaekim@ pusan.ac.kr)

Received: 14 August 2017 - Discussion started: 29 August 2017

Revised: 29 October 2017 - Accepted: 7 November 2017 - Published: 15 November 2017

\begin{abstract}
This paper verifies and corrects the Ozone Mapping and Profiler Suite (OMPS) nadir mapper (NM) level 1B v2.0 measurements with the aim of producing accurate ozone profile retrievals using an optimal-estimation-based inversion method to fit measurements in the spectral range 302.5$340 \mathrm{~nm}$. The evaluation of available slit functions demonstrates that preflight-measured slit functions represent OMPS measurements well compared to derived Gaussian slit functions. Our initial OMPS fitting residuals contain significant wavelength and cross-track-dependent biases, resulting in serious cross-track striping errors in the tropospheric ozone retrievals. To eliminate the systematic component of the fitting residuals, we apply "soft calibration" to OMPS radiances. With the soft calibration the amplitude of fitting residuals decreases from $\sim 1$ to $0.2 \%$ over low and middle latitudes, and thereby the consistency of tropospheric ozone retrievals between OMPS and the Ozone Monitoring Instrument (OMI) is substantially improved. A common mode correction is also implemented for additional radiometric calibration; it improves retrievals especially at high latitudes where the amplitude of fitting residuals decreases by a factor of $\sim 2$. We estimate the noise floor error of OMPS measurements from standard deviations of the fitting residuals. The derived error in the Huggins band $(\sim 0.1 \%)$ is twice the OMPS L1B measurement error. OMPS noise floor errors constrain our retrievals better, leading to improving information content of ozone and reducing fitting residuals. The final precision of the fitting residuals is less than $0.1 \%$ in the low and middle latitudes, with $\sim 1$ degrees of freedom for signal for the tro-
\end{abstract}

pospheric ozone, meeting the general requirements for successful tropospheric ozone retrievals.

\section{Introduction}

Atmospheric ozone has very different roles depending on its altitude. About $90 \%$ of the total ozone is in the stratosphere, protecting the Earth's life from harmful solar ultraviolet (UV) radiation that can cause skin cancer and immune system suppression. The remaining $10 \%$ in the troposphere shows dangerous effects as a major component of photochemical smog at surface level and as a short-lived greenhouse gas in the upper troposphere, whereas in the middle troposphere it plays a beneficial role in chemically cleaning the atmosphere as a precursor of hydroxyl radicals $(\mathrm{OH})$. Therefore, vertical ozone profiles should be monitored to improve our understanding of the chemical and physical functions of this important trace gas. Space-based monitoring of ozone profiles including the troposphere from backscattered UV radiation has been available since the launch of the Global Ozone Monitoring Experiment (GOME; European Space Agency, 1995) on board the second European RemoteSensing Satellite (ERS-2) in April 1995. Its successors continued the role of GOME for atmospheric ozone monitoring with SCanning Imaging Absorption SpectroMeter for Atmospheric CHartographY (SCIAMACHY; Bovensmann et al., 1999) aboard the Environmental Satellite (ENVISAT), GOME-2s (EUMETSAT, 2006) aboard the MetOp-A and 
MetOp-B and Ozone Monitoring Instrument (OMI; Levelt et al., 2006) flown on the EOS Aura spacecraft. The high performance of OMI ozone profile retrievals in both stratosphere and troposphere has been demonstrated through extensive validation efforts using ozonesondes, aircraft, satellite data and ground-based total ozone data (Pittman et al., 2009; Liu et al., 2010; Bak et al., 2013b, 2015; Huang et al., 2017a, b). However, a portion of OMI radiance measurements has been affected by the partial blockage of the instrument's entrance slit, a problem termed the row anomaly, which started in 2007 and grew serious in January 2009 (Schenkeveld, 2017). The Ozone Mapping and Profiler Suite (OMPS) aboard the Suomi National Polar-Orbiting Partnership (NPP) satellite that launched in 2011 (Flynn et al., 2014) represents the next generation of US instruments. They will continue the role of OMI in monitoring total ozone and ozone vertical profiles, together with the TROPOspheric Monitoring Instrument (TROPOMI), to be launched on board the Sentinel-5 Precursor satellite in 2017 (Veefkind et al., 2012). OMPS is a sensor suite which consists of three instruments: the nadir mapper (OMPS-NM), the nadir profiler (OMPS$\mathrm{NP}$ ) and the limb profiler (OMPS-LP). The OMPS-NM is designed to measure the daily global distribution of total column ozone with an $110^{\circ}$ cross-track field of view (FOV), similarly to OMI and the Total Ozone Monitoring Spectrometer (TOMS) series (Bhartia and Wellemeyer, 2002). OMPS-NP is an ozone profiler sensor measuring the vertical ozone profiles in the upper stratosphere, similarly to the Solar Backscatter Ultraviolet (SBUV/2) series (Bhartia et al., 2013). The OMPS-LP is designed to measure ozone profiles in the stratosphere and upper troposphere at high vertical resolution, similarly to the Microwave Limb Sounder (MLS). Both OMPS-NP and OMPS-LP are ozone profile sensors but lack sensitivity to the troposphere due to the spectral coverage of $250-290 \mathrm{~nm}$ and the viewing geometry, respectively. Therefore, OMPS-NM is the only candidate for global monitoring of ozone profiles down to the troposphere, even though its spectral resolution of $1.0 \mathrm{~nm}$ does not fully resolve the ozone absorption band features in the Huggins band and its spectral coverage of $300-380 \mathrm{~nm}$ is insufficient to retrieve stratospheric ozone profiles. The retrieval of ozone profiles including tropospheric ozone from OMPS-NM measurements has not yet been presented in the literature. The present effort fills the gap between OMI and upcoming satellite observations.

The final goal of this study is to demonstrate the successful performance of ozone profiles and tropospheric ozone retrievals from only OMPS-NM measurements. Hereafter, we refer to OMPS-NM simply as OMPS. The retrieval algorithm used in this study is based on the Smithsonian Astrophysical Observatory (SAO) ozone profile algorithm that was developed for GOME (Liu et al., 2005) and OMI (Liu et al., 2010). The SAO OMI algorithm is based on an optimal estimation inversion (Rodgers, 2000) combined with accurate wavelength/radiometric calibration, forward model simula- tion and good a priori knowledge. This algorithm has been implemented for ozone profile and $\mathrm{SO}_{2}$ retrievals from the GOME-2 instrument (Cai et al., 2012; Nowlan et al., 2011) and will be adapted to ozone profile retrievals from upcoming geostationary UV/VIS spectrometers including the Geostationary Environmental Monitoring Spectrometer (GEMS; Bak et al., 2013a) and Tropospheric Emissions: Monitoring of Pollution (TEMPO) instrument (Chance et al., 2013; Zoogman et al., 2017) for monitoring air quality over North America and eastern Asia, respectively. OMPS has a similar instrument concept to OMI, GEMS and TEMPO and hence the application of the similar retrieval algorithms to these measurements will provide an excellent opportunity for long-term trend analysis of ozone profiles, especially in the troposphere. The OMI algorithm is very similar to our OMPS algorithm, but it needs additional optimization for OMPS. In this paper we focus largely on characterizing OMPS measurements (1) through the cross-correlation between OMPS irradiances and a high-resolution solar reference to be used in the verification of OMPS slit function measurements and the characterization of the wavelength registration and (2) through extracting the systematic and random components of fitting residuals between measured and calculated normalized radiances to be used in radiometric and measurement error calibrations, respectively. Several companion papers to follow will deal with the detailed error analysis, retrieval characteristics of the retrieved ozone profiles and validation of retrievals.

The paper is divided into four sections: first, we give a description of OMPS-NM level 1B (L1B) v2.0 data (Jaross, 2017) and the ozone profile algorithm in Sect. 2. Section 3 discusses the wavelength/slit function calibrations and measurement corrections for radiance and measurement errors, respectively. Conclusions are in Sect. 4.

\section{Data and method}

\subsection{OMPS measurements}

The Suomi NPP satellite is a NOAA/NASA scientific partnership that was launched in 2011 into a $824 \mathrm{~km}$ sunsynchronous polar orbit with ascending node equatorcrossing time at 13:30 local time. Routine operations began in 2012. Suomi NPP carries five instruments: the Visible/Infrared Imager Radiometer Suite (VIIRS), the Crosstrack Infrared Sounder (CrIS), the Advanced Technology Microwave Sounder (ATMS), the Ozone Mapping and Profile Suite (OMPS) and the Clouds and the Earth's Radiant Energy System (CERES). OMPS is a key instrument on Suomi NPP. The sensor suite has both nadir and limb modules. The nadir module combines two sensors: the nadir mapper for measuring total column ozone and the nadir profiler for ozone vertical profile. The limb profiler module is designed to measure vertical ozone profiles with high vertical reso- 
Table 1. Surface and atmospheric input parameters and cross section data used in forward model calculations.

\begin{tabular}{ll}
\hline Forward model parameters & Data source \\
\hline $\mathrm{O}_{3}$ cross sections & Brion et al. (1993) \\
Ozone profile $^{\mathrm{a}}$ & OMI ozone profiles from Liu et al. (2010) \\
Temperature profile, surface/ & Daily National Centers for Environmental Prediction (NCEP) final (FNL) \\
tropopause pressure & operational global analysis data (http://rda.ucar.edu/datasets/ds083.2/) \\
Surface albedo & OMI surface climatology (Kleipool et al., 2008) \\
Cloud fraction & Derived at 347 nm \\
Cloud-top pressure $^{\mathrm{b}}$ & OMPS cloud optical centroid pressures (OCPs; Vasilkov et al., 2014) \\
\hline
\end{tabular}

${ }^{\text {a }}$ OMI ozone profiles retrieved at $48 \times 52 \mathrm{~km}^{2}$ with spatial coadding and then interpolated to $5^{\circ} \times 5^{\circ}$ to fill bad pixels. ${ }^{\mathrm{b}}$ OCPs retrieved from OMPS-NM L1B v1.0 measurements using a rotational Raman scattering cloud algorithm.
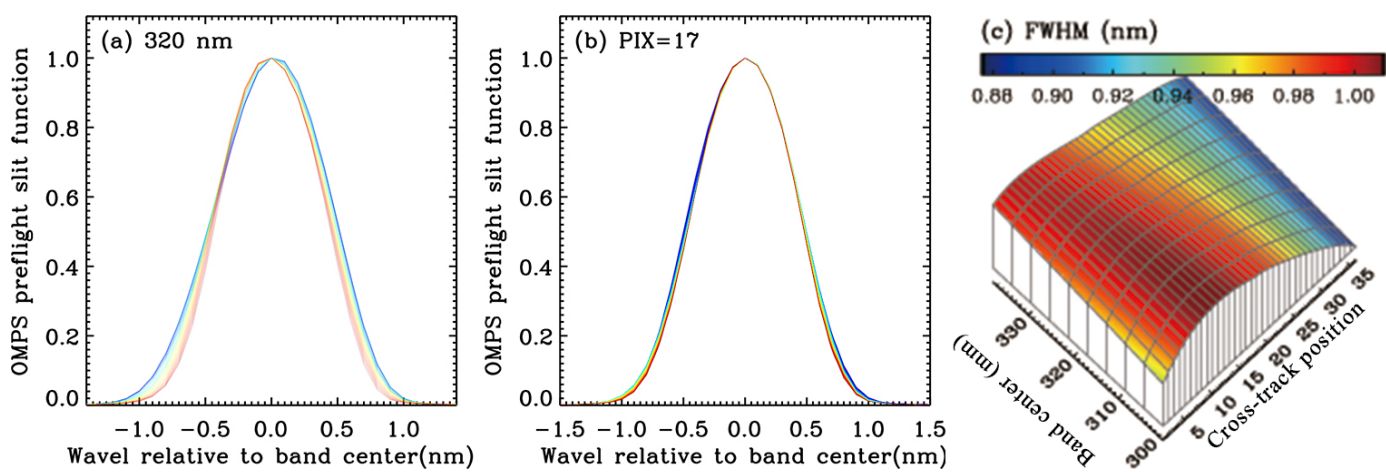

Figure 1. (a) OMPS preflight slit function at $320 \mathrm{~nm}$ band center, with colors representing different cross-track positions from 1 (blue) to 36 (red). (b) Same as (a) but for the 17th cross-track position, with colors representing different wavelengths from 300 (blue) to $340 \mathrm{~nm}$ (red). (c) Full width at half maximum (FWHM) in nm as functions of cross-track positions ( $x$ axis) and band center wavelengths ( $y$ axis) ranging from 300 to $340 \mathrm{~nm}$.

lution from the upper troposphere/lower stratosphere to the mesosphere. The OMPS-NM employs a 2-D CCD that samples spectrally in one dimension and spatially in the other, similarly to OMI. It has a $110^{\circ}$ cross-track field of view, resulting in $2800 \mathrm{~km}$ instantaneous swath coverage at the Earth's surface; this is sufficient to provide daily global coverage. It makes 400 swath lines per orbit with 36 cross-track measurements per swath line, resulting in a nadir footprint of $50 \mathrm{~km} \times 50 \mathrm{~km}$ in its nominal configuration. Note that OMPS L1B data used in this investigation contain 36 cross-track pixels, because the L1B processing in the NASA Ozone SIPS retains the two central (near-nadir) instantaneous fields of views (IFOVs, $30 \mathrm{~km} \times 50 \mathrm{~km}$ and $20 \mathrm{~km} \times 50 \mathrm{~km}$ ), without aggregating them into the nominal $50 \mathrm{~km} \times 50 \mathrm{~km}$ pixel. The spectral coverage is from 300 to $380 \mathrm{~nm}$ with a spectral resolution of $\sim 1.0 \mathrm{~nm}$ and a sampling of $0.42 \mathrm{~nm}$. The OMPS level 0 to $1 \mathrm{~b}$ processor was recently updated from version 1.0 to 2.0. The satellite measurements from the OMPS-NM instrument used in this study are from version 2 of the NMEVL1B data product (Jaross, 2017) available from the NASA Goddard Earth Sciences Data and Information Services Center (GES DISC). The data consist of calibrated Earth-view radiance and solar irradiance data measured by the instrument between 300 and $380 \mathrm{~nm}$. Seftor et al. (2014) documented many aspects of the previous version of the data set that remain the same, but a number of changes for the V2 data set do reflect advances in the characterization of the NM sensor (Seftor and Jaross, 2017), which are relevant to this study. These are summarized as follows: (1) recalculation of instrument band-pass functions in the $300-310 \mathrm{~nm}$ region affected by the dichroic element of the nadir instrument, (2) improved wavelength registration, (3) an update to the instrument radiance calibration and (4) improvement to the stray-light correction. The wavelengths below $302 \mathrm{~nm}$ are not used in this study, according to the recommendation of the OMPS science team.

\subsection{OMPS simulations}

We use the Vector LInearized Discrete Ordinate Radiative Transfer (VLIDORT) model (Spurr, 2006, 2008) to simulate OMPS radiances. VLIDORT is also able to simulate the analytic derivatives of radiance with respect to any atmospheric or surface parameter due to its full linearization capability. The polarization of light are taken into account in the VLIDORT calculation, but the ring spectrum is modeled using a single-scattering RRS model (Sioris and Evans, 2000). We consider only Rayleigh scattering (no aerosol) and ozone ab- 

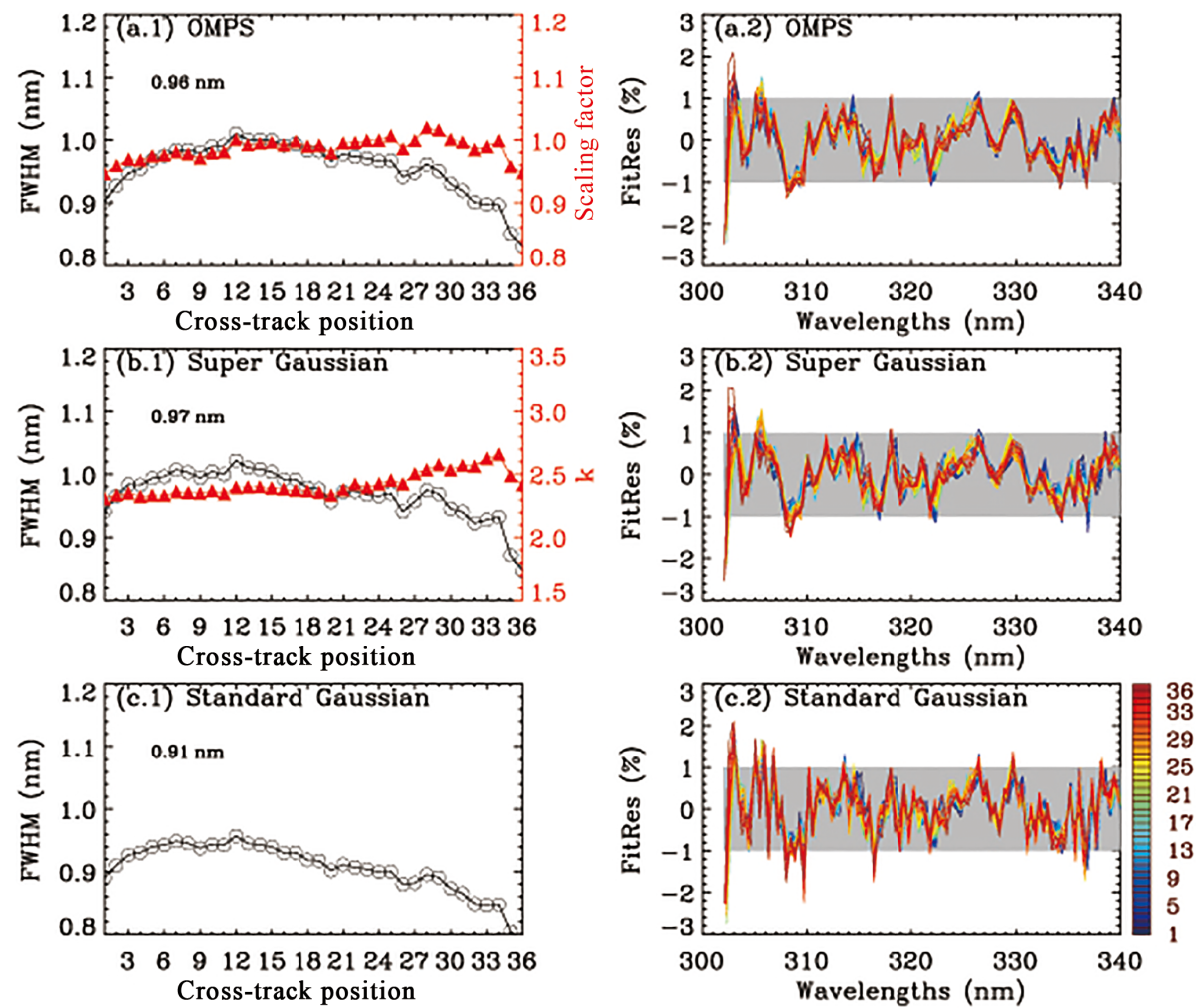

Figure 2. (a1, b1, c1) Slit function parameters as a function of cross-track position (1th-36th) for three different slit functions from OMPS irradiance measurements (302-340 nm) for orbit 7132 on 14 March 2013. The legends represent the FWHM averaged over all spectral pixels. $(\mathbf{a} 2, \mathbf{b 2}, \mathbf{c 2})$ The corresponding relative fitting residuals between measured and simulated irradiance spectra.

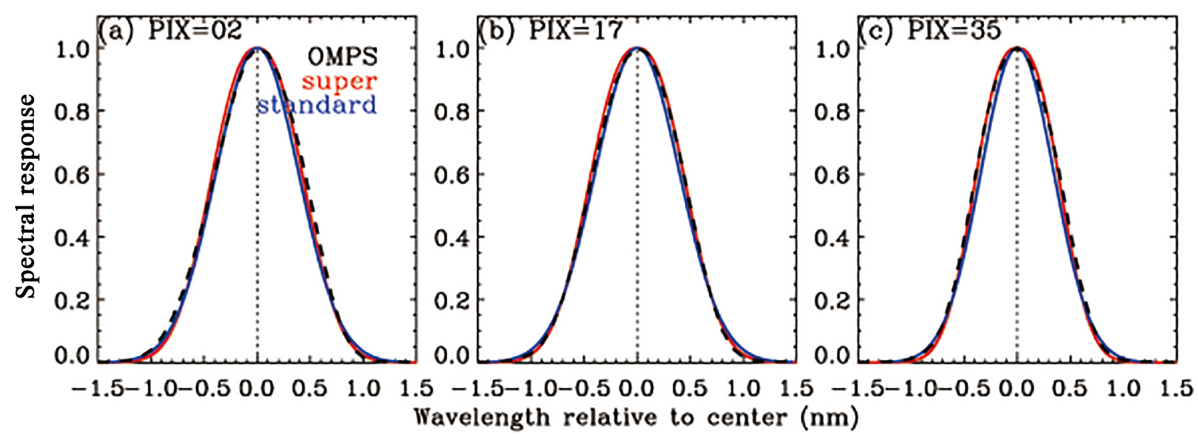

Figure 3. Comparison of OMPS-measured slit measurements (black) and derived slit functions assuming a standard Gaussian (red) and super Gaussian (blue) for orbit 7132.

sorption (no other trace gases), with Lambertian reflectance assumed for the surface and for clouds. Clouds are treated as a Lambertian reflector at cloud top, with a fixed albedo of 0.8 unless it is fully cloudy, so that the cloud albedo $(>0.80)$ can be derived. Cloud fraction is required to simulate partial clouds as the weighted average between clear and cloudy scenes using the independent pixel approximation (IPA). The forward model inputs used in VLIDORT are listed in Table 1.

\subsection{OMPS ozone profile retrievals}

The inversion from backscattered UV measurements to the state of the atmosphere is performed using the well-known optimal estimation method (Rodgers, 2000). It calculates the a posteriori solution by iteratively and simultaneously minimizing the cost function consisting of the sum of the squared differences between measured and simulated radiances and between retrieved and a priori state vectors, constrained by measurement error covariance matrix and a priori error covariance matrix. The a posteriori solution and cost function 

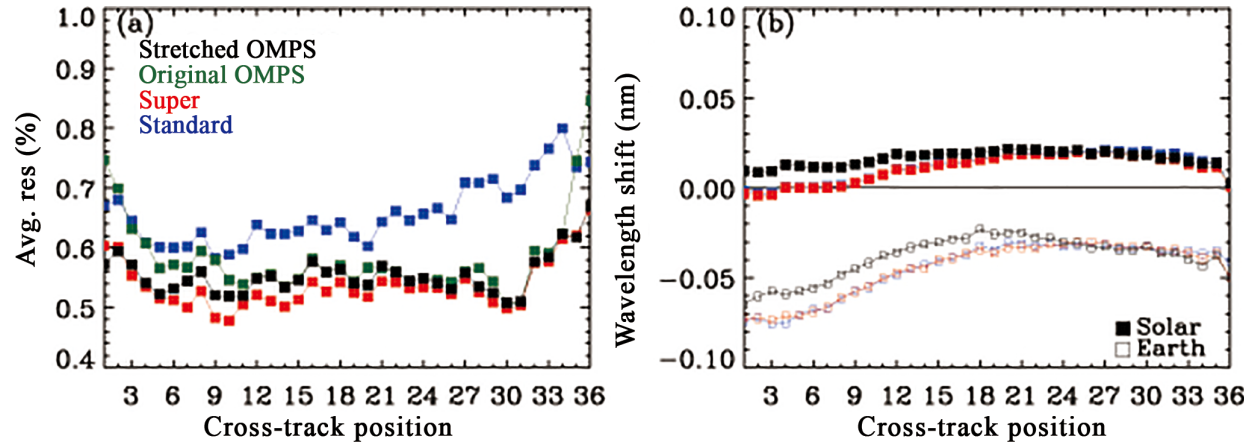

Figure 4. Same as Fig. 2 but for (a) average fitting residuals (\%) as a function of cross-track positions. The green line represents the fitting residuals with measured OMPS slit functions without fitting a scaling factor. (b) Wavelength shifts between OMPS irradiance and reference spectrum (filled symbols) and between OMPS radiance at the middle swath line and reference spectrum (opened symbols).

(a) OMPS SCO

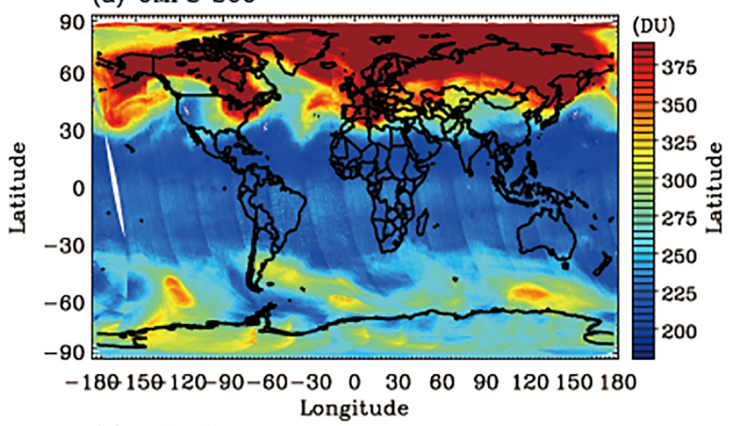

(c) OMI SCO

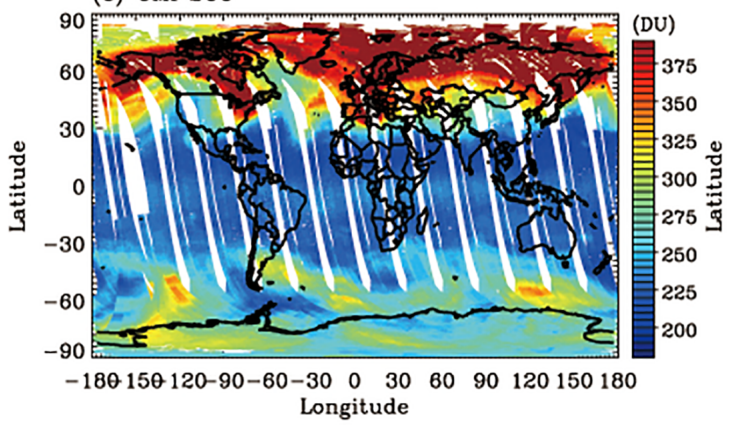

(b) OMPS TCO

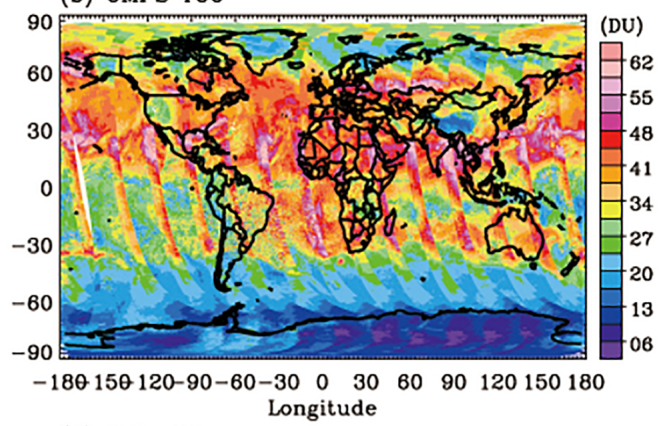

(d) OMI TCO

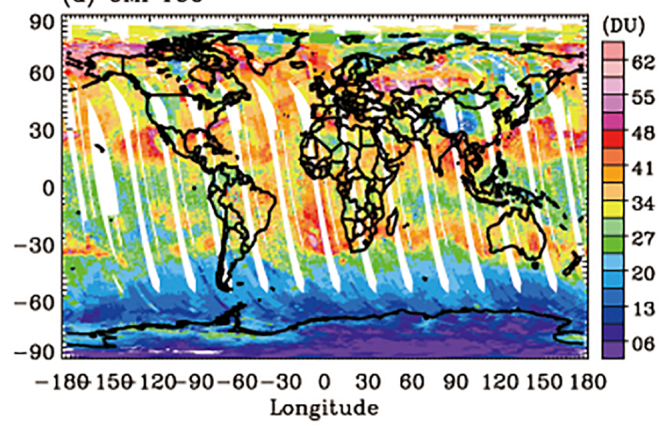

Figure 5. Maps of stratospheric and tropospheric ozone column on 14 March 2013, retrieved from OMPS (a, b) without any correction and OMI (c, d) measurements, respectively.

can be written

$$
\begin{aligned}
\boldsymbol{X}_{i+1} & =\boldsymbol{X}_{i}+\left(\mathbf{K}_{i}^{T} \mathbf{S}_{y}^{-1} \mathbf{K}_{i}+\mathbf{S}_{\mathrm{a}}^{-1}\right)^{-1}\left[\mathbf{K}_{i}^{T} \mathbf{S}_{y}^{-1}\left(\boldsymbol{Y}-\boldsymbol{R}\left(\boldsymbol{X}_{i}\right)\right)\right. \\
& \left.-\mathbf{S}_{\mathrm{a}}^{-1}\left(\boldsymbol{X}_{i}-\boldsymbol{X}_{\mathrm{a}}\right)\right] \\
\chi^{2} & \left.=\| \mathbf{S}_{y}^{-\frac{1}{2}}\left\{\mathbf{K}_{i}\left(\boldsymbol{X}_{i+1}-\boldsymbol{X}_{i}\right)-\left[\boldsymbol{Y}-\boldsymbol{R}\left(\boldsymbol{X}_{i}\right)\right]\right\}\right) \|_{2}^{2} \\
& +\left\|\mathbf{S}_{\mathrm{a}}^{-\frac{1}{2}}\left(\boldsymbol{X}_{i+1}-\boldsymbol{X}_{\mathrm{a}}\right)\right\|_{2}^{2}
\end{aligned}
$$

The inputs to the optimal estimation are defined as follows. $\boldsymbol{X}$ is the state vector to be retrieved, consisting of ozone profiles as well as other geophysical parameters and spectroscopic parameters affecting the observed radiances and hence the retrieval of ozone profile. The 24 partial columns of ozone in DU are retrieved at 25 pressure levels that are initially set to $P_{i}=2^{-i / 2}$ atm for $i=0,1, \ldots 23(1 \mathrm{~atm}=1013.25 \mathrm{hPa})$ with the top of the atmosphere at $0.087 \mathrm{hPa}$ for $P_{24}$. The geophysical parameters include effective surface albedo and cloud fraction. The calibration parameters consist of two wavelength shift parameters between radiances and irradiances and between radiances and ozone cross sections and two scaling parameters for the ring effect and mean fitting residuals; these may not be accounted for properly in radiometric calibration. The a priori data for ozone are one of the key optimal estimation inputs, because the retrieval so- 
lution comes mainly from a priori information rather than measurement information where the instrument sensitivity to the true ozone profile is insufficient. The a priori value $\left(\boldsymbol{X}_{\mathrm{a}}\right)$ and a priori error covariance $\left(\mathbf{S}_{\mathrm{a}}\right)$ of ozone is taken from the tropopause-based ozone profile climatology that is optimized to represent the dynamical ozone variability in the upper troposphere and lower stratosphere (Bak et al., 2013b). The measurement vector $\boldsymbol{Y}$ is defined as the logarithm of the earthshine radiances normalized to the daily solar irradiance. $\mathbf{S}_{y}$ is a measurement error covariance matrix that is assumed to be a diagonal matrix with diagonal elements being the squares of the assumed measurement errors. We use OMI noise floor errors $(0.4 \%$ below $310 \mathrm{~nm}, 0.2 \%$ above, Huang et al., 2017a) as our preliminary measurement constraint and then derive OMPS noise floor errors specified in Sect. 3.4. $\boldsymbol{R}(\boldsymbol{X})$ is the calculated radiances corresponding to $\boldsymbol{X}$. $\mathbf{K}$ is a weighting function matrix representing partial derivatives of the forward model with respect to the atmospheric parameters, $\mathbf{K}_{i j}=\partial R_{i}(\boldsymbol{X}) / \partial \boldsymbol{X}_{j}$. More detailed descriptions can be found in Liu et al. (2010).

\section{Results}

\subsection{Slit function and wavelength calibration}

It is essential to investigate the best knowledge of the instrument slit function to convolve a high-resolution solar reference spectrum for wavelength calibration as well as to convolve high-resolution trace gas cross sections for simulations of earthshine spectra. A triangular bandpass with a fixed bandwidth of $1.1 \mathrm{~nm}$ has been typically used for the Total Ozone Monitoring Instrument (TOMS), SBUV and SBUV/2 monochromators. Slit functions of spectrometers such as OMI and GOME1/2 have been measured prior to launch using a tunable laser or analytically derived assuming a Gaussian-type shape if measured slit functions are unavailable or inaccurate. The OMPS preflight slit functions were characterized for each CCD pixels (196 band centers and 36 cross-track positions), which has been adopted and modified for OMPS trace-gas retrievals such as in Yang et al. (2013, 2014) and Gonzalez Abad et al. (2016). The slit function modification has been accomplished in the previous works (Yang et al., 2013, 2014) by stretching and shrinking the slit widths, i.e., by applying a wavelength-dependent scaling factor to the OMPS-measured slit functions. According to Yang et al. $(2013,2014)$, we fit the scaling factor as a slit parameter, so that variations in measured slit functions before and after launch could be taken into account.

Figure 1a shows an example of measured OMPS slit functions at $320 \mathrm{~nm}$, illustrating that their shapes seem to be Gaussian and vary considerably over cross-track pixels, especially near the wings. Note that the 36 cross-track positions are denoted from 1 at the left edge and 36 at the right edge. The slit function shapes at the 17 th cross-track posi- tion are nearly consistent over wavelengths that we are focusing on for ozone retrievals (Fig. 1b). Figure 1c displays the full width at half maximum (FWHM) including dependencies in both dimensions of the detector arrays. The spectral variation of the slit widths is insignificant (FWHMs vary by less than $0.01 \mathrm{~nm}$ ), whereas average slit widths vary significantly across track by over $0.1 \mathrm{~nm}$. This characteristic of measurement slit functions confirms that we should consider their cross-track dependence for OMPS slit functions, but their wavelength dependence is ignorable, so we can avoid the time-consuming convolution process.

We evaluate the usefulness of these measured slit functions for fitting both OMPS radiance and irradiance against the analytical slit functions assuming both standard Gaussian and super Gaussian distributions. We note all the Gaussian shapes used in this analysis are assumed to be symmetric. The Gaussian slit function is expressed as

$\mathbf{S}(\lambda)=\frac{k}{2 w \Gamma\left(\frac{1}{k}\right)} \exp \left[-\left|\frac{\Delta \lambda}{w}\right|^{k}\right]$,

where $k$ is the shape factor and $w$ is the slit width, with relative wavelength to band center wavelength, $\Delta \lambda$. This function can describe a wide variety of shapes just by varying $k$; for $k=2$ it becomes the standard Gaussian and $w$ represents the half width at $1 / e$ intensity $(\mathrm{FWH}=2 \sqrt{\ln 2} w)$. Compared to the standard Gaussian, the super Gaussian has broader peaks at the top and thinner wings if $k$ is larger than 2 , whereas it has sharper peaks and longer tails if $k$ is smaller than 2. $w$ of the super Gaussian function represents the halfwidth at $1 /$ eth intensity $(\mathrm{FWHM}=2 \sqrt[k]{\ln 2})$. The symmetric or asymmetric standard Gaussian has been commonly assumed to derive OMI, GOME and GOME-2 slit functions (Liu et al., 2005, 2010; Nowlan et al., 2011; Cai et al., 2012; Munro et al., 2016). Recently the hybrid combination of standard and flat-top Gaussian functions has been implemented for characterizing OMI laboratory measurements of slit functions (Dirksen et al., 2006) and deriving airborne instrument slit functions (Liu et al., 2015a, b; Nowlan et al., 2016). The concept of this hybrid Gaussian function is very similar to the super Gaussian but is a rather complex with more slit parameters. The super Gaussian function was introduced and tested as an analytical slit function by Beirle et al. (2017) and Sun et al. (2017a, b).

In general, when accurate measurements of slit functions are not available, the instrument line shape of satellite observation is typically assumed to be the same for both radiance and irradiance measurements and then can be determined better from irradiances due to lack of atmospheric interference. We simultaneously and iteratively determine the wavelength and slit calibration parameters through crosscorrelation of the measured OMPS irradiances to simulated solar irradiances from a well-calibrated, high-resolution solar irradiance reference spectrum (Chance and Kurucz, 2010). 

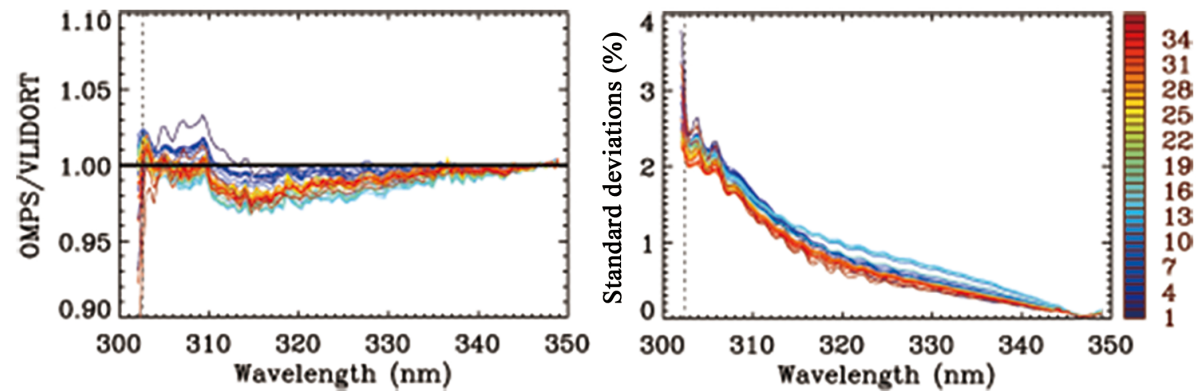

Figure 6. (a) Soft calibration spectrum derived from OMPS-measured to simulated radiance ratio at initial iteration, as a function of wavelength ranging from 302 to $350 \mathrm{~nm}$. The vertical dotted line indicates $302.5 \mathrm{~nm}$. OMPS data used in this calculation are limited to tropical clear-sky conditions (latitude $< \pm 15^{\circ}$, cloud fraction $<0.1$, surface reflectivity $<0.1$ ) for 25 days between 1 and 25 March 2013 . Forward model inputs listed in Table 1 are used for OMPS simulations. (b) Standard deviations of fitting residuals. Different colors represent various cross-track positions.

(a) OMPS SCO

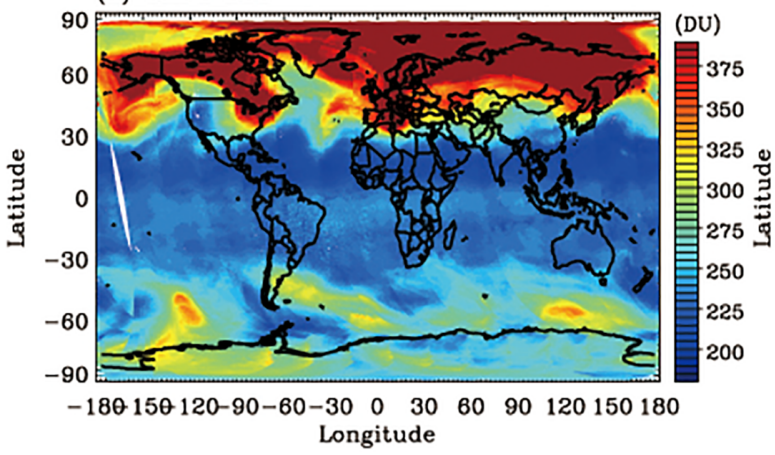

(b) OMPS TCO

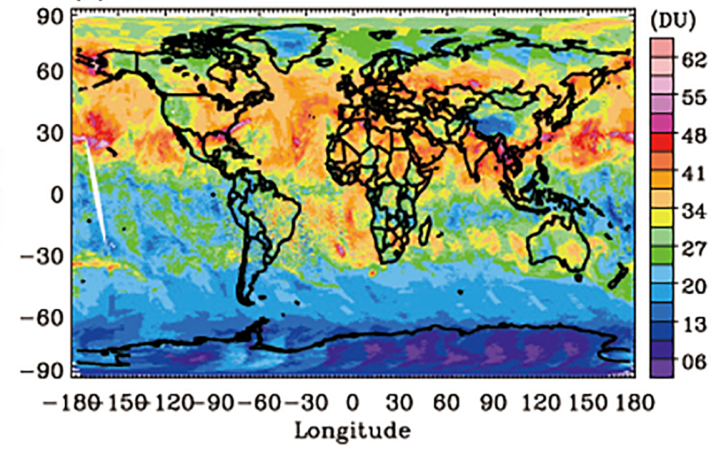

Figure 7. Same as Fig. 5a and b but for OMPS ozone retrievals with soft calibration.

The simulation of solar irradiance, $I_{\mathrm{S}}$ is described as

$I_{\mathrm{S}}(\lambda)=A I_{o}(\lambda+\Delta \lambda) \times \sum_{i=0}^{2} P_{i}\left(\lambda-\lambda_{\mathrm{avg}}\right)^{i}$

where $I_{O}$ is the convolved high-resolution solar reference spectrum with assumed slit functions, $A$ is the scaling parameter for $I_{0} . \lambda+\Delta \lambda$ indicates the process of wavelength calibration (e.g., shift and squeeze); only the wavelength shift is considered in this study. $P_{i}$ represents the coefficients of a scaling polynomial (third order in this study). This approach was firstly introduced by Caspar and Chance (1997) and is widely used for wavelength and slit function calibrations in trace gas retrievals from UV/visible measurements.

In this experiment, the slit parameters, $w$ and $k$ or slit scaling are fitted from daily measured OMPS irradiances over the wavelength range $302-340 \mathrm{~nm}$ at each cross-track position. Note that this slit calibration ignores the wavelength dependence for deriving analytic slit functions and slit scaling to the measured slit functions; this is a good approximation based on Fig. 1b as the wavelength dependence of the slit functions is small. However the variation of the slit shape with wavelength could be considered with OMPS preflightmeasured slit functions given for every CCD dimension if it becomes necessary. The left panels of Fig. 2 compare the derived slit parameters from OMPS irradiances using different functions. The red line of Fig. 2a1 shows that a slight change of the preflight-measured slit functions is required to model the OMPS irradiance measurements, by up to $4 \%$ at both edges. Therefore the benefit of fitting measured slit functions over fixing them is found to be trivial $(\sim 0.001 \%)$ at nadir cross-track pixels (12-30th); for edge pixels, the improvement in fitting residuals is more noticeable, up to $0.18 \%$. The shape factor $(k)$ of the derived super Gaussian functions is found to be $\sim 2.3$ for left swath and $\sim 2.5$ for right swath (Fig. 2b1), implying that they have broader peaks and thinner wings compared to the standard Gaussian if slit widths are equal. The slit widths of three different slit functions show similar variations with respect to cross-track positions. The FWHMs vary from the widest at $\sim 12$ th cross-track position to the narrowest at the edges, but they are significantly narrower at the rightmost cross-track positions than at the leftmost ones. Compared to the standard Gaussian slit widths, the super Gaussian slit widths show a much better agreement with measured slit widths; the average difference of slit widths between measured and super (standard) Gaussian functions is $\sim 0.01(0.05) \mathrm{nm}$. In Fig. 3, an example of the 

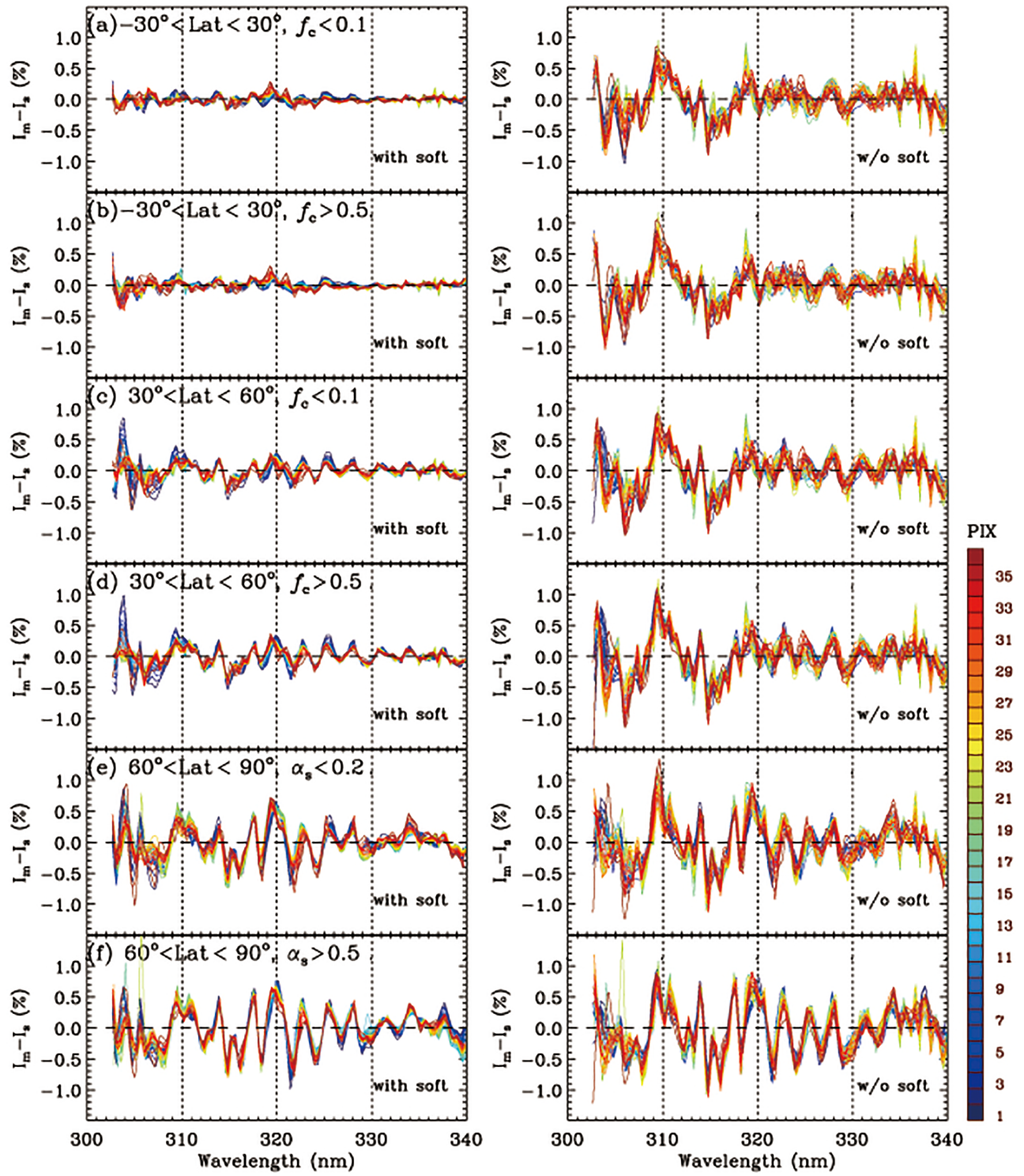

Figure 8. Comparison of fitting residuals on 14 March 2013 with (left) and without (right) soft calibration for six cases: (a-b) Tropics and (c-d) midlatitudes each for clear sky (effective cloud fraction, fc $<0.1$ ) and cloudy ( fc $>0.5$ ) conditions and (e-f) high latitudes for snow-free and snow-covered surface conditions. Different colors represent different cross-track positions.

derived slit functions and fitted preflight slit functions shows that the shapes are very similar.

The wavelength calibrations using different slit functions are characterized for the ozone fitting window and are shown in Fig. 4b. The shift parameter is determined from irradiance and radiance at second cross-correlation step after slit parameters are determined from irradiances at first crosscorrelation step. Note that the wavelength shifts fitted between the first and second steps are very similar, indicating little correlation between slit and wavelength calibration parameters. This analysis indicates that the accuracy of wavelength registration in ozone fitting wavelengths is $0.03-$ $0.06 \mathrm{~nm}$ for earthshine measurements and $<0.02 \mathrm{~nm}$ for solar measurements with consistent variation over all cross-track pixels. These wavelength errors are larger than those reported by Seftor et al. (2014) due to different fitting windows. They use $350-380 \mathrm{~nm}$ where prominent solar Fraunhofer absorption lines exist and the interference with ozone absorption lines are negligible. Furthermore, the wavelength calibration results using OMPS-measured slit functions show different characteristics from those using both Gaussian-type slit functions, especially over left cross-track pixels. The different wavelength shifts are likely, because the original OMPS slit functions show slight asymmetry and are used in the wavelength calibration of L1B data. There exists a $\sim 0.07 \mathrm{~nm}$ shift between irradiances and radiance. In ozone retrieval algo- 

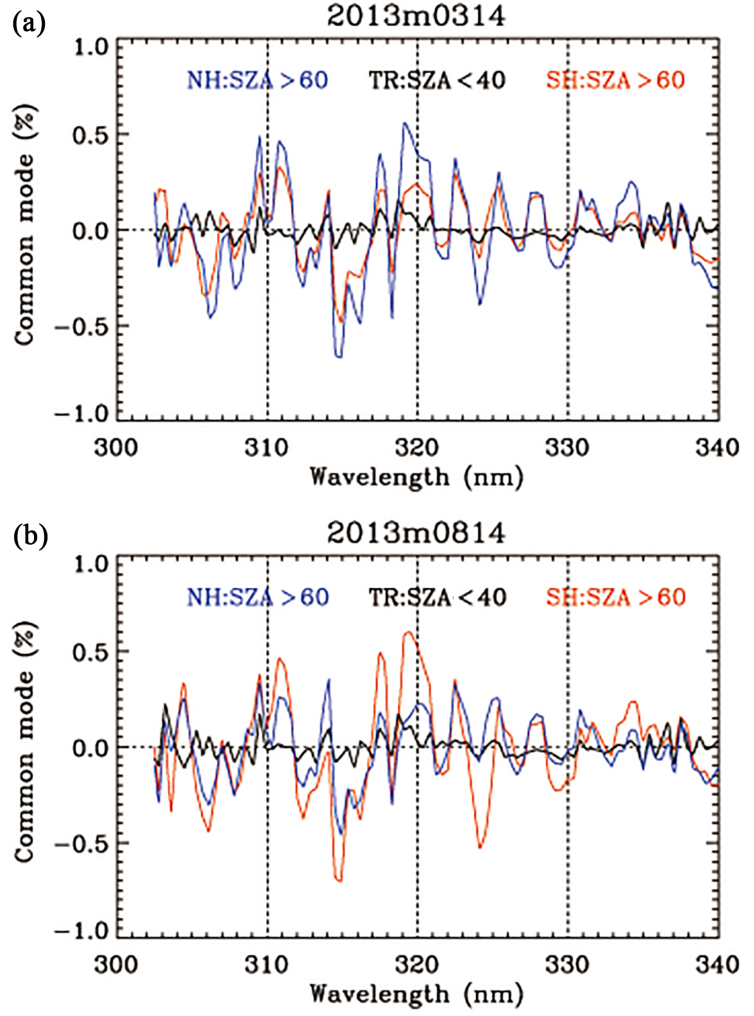

Figure 9. Common mode spectra derived from final fitting residuals at the 17th cross-track position using 1 day of measurements in March (a) and August (b), respectively. Note that tropical residuals are derived from near-clear-sky conditions where SZA $<40^{\circ}$, cloud fraction $<0.1$ and surface albedo $<0.1$. No special data screening is applied for polar residual spectra, except for $\mathrm{SZA}>60^{\circ}$.

rithm we shift neither radiance nor irradiance to a reference spectra before retrievals, but the shift between irradiance and radiance is adjusted during ozone retrievals to account for the on-orbit variations of wavelength shifts as mentioned in Sect. 2.3.

The right columns of Fig. 2 compare the impact of different slit functions on spectral fitting residuals of solar irradiances, together with the average fitting residuals as a function of cross-track position in Fig. 4a. Measured solar spectra are mostly within an average of $\sim 1 \%$ of modeled solar spectra, except for the first few wavelengths. Based on these fitting results, we revise the fitting window to $302.5-340 \mathrm{~nm}$. The fitting residuals using a derived standard Gaussian function are the worst for all cross-track positions. On the other hand, the super Gaussian slit function similarly represents the measured slit function but slightly improves the fitting accuracy at the 6-18 cross-track positions (Fig. 4a). However, the benefit of using the super Gaussian function for fitting OMPS radiances over the standard Gaussian function is insignificant within $0.02 \%$ (not shown here). These results agree well with Beirle et al. (2017), who demonstrated the similar benefit of using standard and super Gaussian slit functions on the OMI and GOME-2 measurements. Moreover, the impact of using different slit functions could be less important for OMPS than OMI and GOME-2 due to its coarser spectral resolution.

In summary, super Gaussian functions are recommended for the OMPS instrument slit functions over the standard Gaussian functions if the on-orbit instrument slit functions largely deviate from the preflight-measured slit functions due to instrument degradation or thermal-induced variation. In the rest of this paper, the measured slit function is used for the analysis of OMPS measurements.

\subsection{Soft calibration}

The OMPS instrument 2-D CCD detector array could be susceptible to artificial cross-track-dependent errors that are commonly seen in OMI trace gas retrievals. To eliminate this impact on the OMI L2 product, soft calibration and postprocessing cross-track smoothing have been typically implemented: the first correction removes the systematic wavelength and cross-track-dependent component in measured radiances (Liu et al., 2010; Cai et al., 2012), whereas the second correction removes cross-track-dependent biases in retrievals (Kurosu et al., 2004; Hörmann et al., 2016). Figure 5 compares our preliminary tropospheric and stratospheric ozone column retrievals with OMI retrievals on 14 March 2013. OMPS stratospheric retrievals show excellent consistency with OMI, even though OMPS measurements do not cover much of the Hartley ozone absorption wavelengths, where most of the vertical information of stratospheric ozone comes from. This is because the separation of stratospheric ozone columns from tropospheric ozone columns is still mainly determined from wavelengths longer than $300 \mathrm{~nm}$ (Bak et al., 2013a). On the other hand, tropospheric ozone retrievals are positively biased with respect to OMI, by amounts that are largely dependent on the OMI cross-track position. Therefore, we decide to include a softcalibration correction in our retrievals to eliminate wavelength and cross-track-dependent errors in OMPS radiances. A general approach to the soft calibration is to characterize systematic differences between measured and computed radiances for scenes in which we could assume that all parameters are known; the tropics were typically selected since ozone variability is relatively small (Liu et al., 2010). OMPSnormalized radiances are simulated with collocated OMI ozone profiles averaged and interpolated onto $5^{\circ} \times 5^{\circ}$ grid cells to fill in bad pixels mostly caused by the row anomaly. Other forward model inputs are described in Sect. 2. We use 25 days of data between 1 and 25 March 2013 under the following conditions: latitude $<15^{\circ} \mathrm{N} / \mathrm{S}$, solar zenith angle $(\mathrm{SZA})<40^{\circ}$, cloud fraction $<0.1$ and surface reflectivity $<0.1$. The systematic and random components of measuredto-simulated radiance ratios are displayed in Fig. 6. Agreement is mostly at the $\pm 2 \%$ level below $310 \mathrm{~nm}$, except at wavelengths shorter than $\sim 302.5 \mathrm{~nm}$ where the systematic 

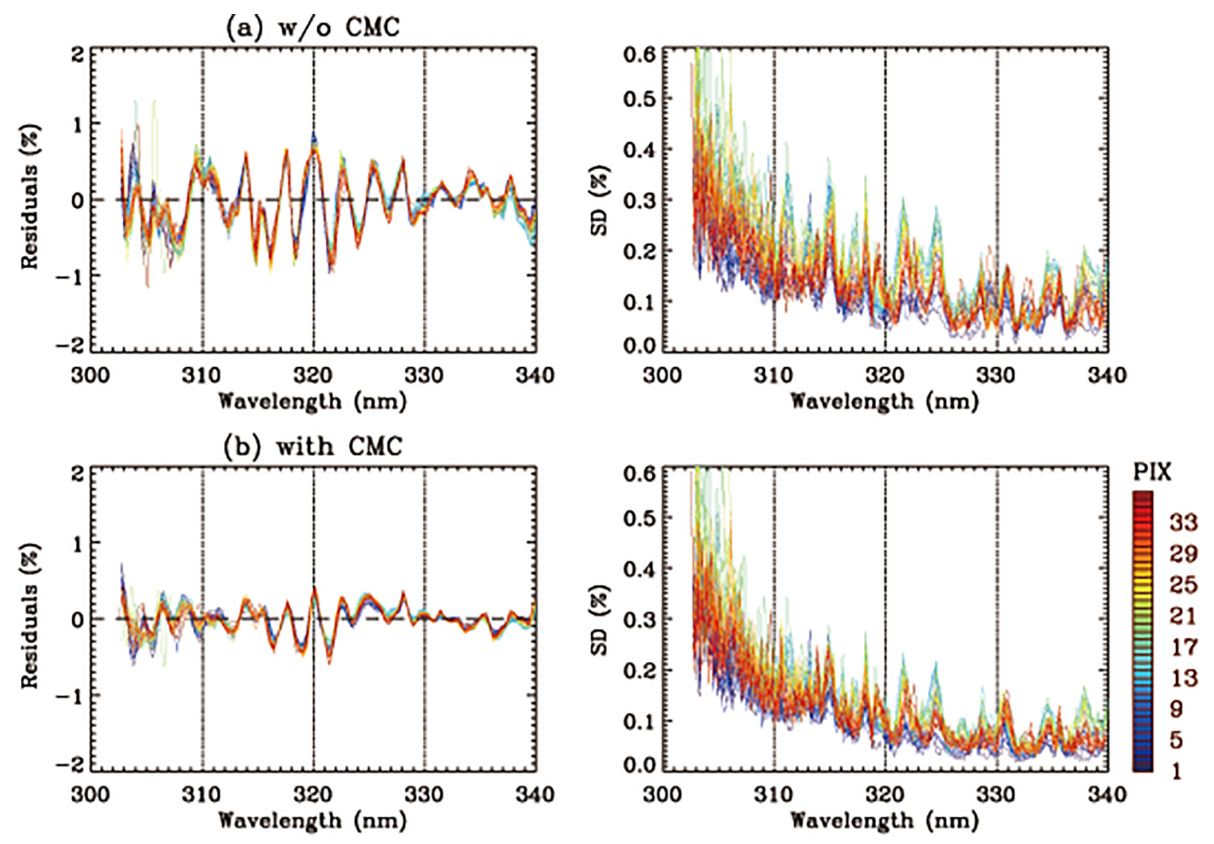

Figure 10. Comparisons of mean fitting residuals $(\%)$ and standard deviations $(\%)$ for latitude $>60^{\circ}$ with different cross-track positions in different colors for one orbit data (6962) on 2 March 2013, without (a) and with (b) common mode correction.

(a) $\mathrm{w} / \mathrm{o} \mathrm{CMC}$
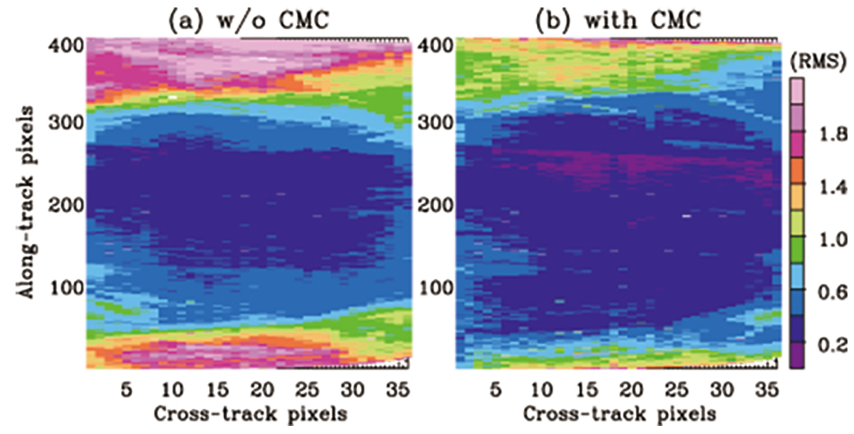

Figure 11. Same as Fig. 10 but for root mean square (rms) of fitting residuals relative to the measurement errors as functions of alongand cross-track pixels. The rms is defined as $\sqrt{\frac{1}{n} \sum_{i}^{n}\left(\frac{\boldsymbol{Y}-R}{\mathbf{S}_{y}^{1 / 2}}\right)^{2}}$. Note that OMI noise floor errors $(0.4 \%$ at wavelengths $<310 \mathrm{~nm}$ and $0.2 \%$ at wavelengths $>310 \mathrm{~nm}$ ) are used to define rms.

biases increase sharply due to the overcorrection of stray light in OMPS v2.0 data processing. For wavelengths longer than $310 \mathrm{~nm}$, OMPS observations show negative biases with maximum of $\sim 3 \%$ at $315 \mathrm{~nm}$. The standard deviations of mean differences steadily increase from longer wavelengths to $302.5 \mathrm{~nm}(2-2.5 \%)$ and then sharply rise up to $\sim 4 \%$. The abnormal features of fitting residuals below $302.5 \mathrm{~nm}$ shown in Figs. 2 and 6 provide a basis for why we select the lower boundary of the ozone fitting window at $302.5 \mathrm{~nm}$. The soft calibration is applied before the fitting starts, by dividing OMPS radiances by the derived correction spectrum just at the initial iteration with the assumption that the systematic biases consistently exist independently of space and time. Figure 7 shows how our tropospheric ozone retrievals are improved with our soft calibration in comparison with the retrievals shown in Fig. 5b. The usefulness of our soft calibration implementation is also evaluated through comparisons of the accuracies of the spectral fitting residuals with and without soft calibration as shown in Fig. 8. The mean fitting residuals without soft calibration are $\sim \pm 1 \%$ at shorter wavelengths $<320 \mathrm{~nm}$ for all latitudes and sky conditions, whereas for longer wavelengths they increase from 0.3 to $0.5 \%$ with increasing latitudes. Our soft calibration dramatically improves the fitting accuracy for both clear and cloudy pixels, especially over the tropics and midlatitude regions; fitting residuals are mostly within $0.2 \%$ at longer wavelengths $>310 \mathrm{~nm}$. In high latitudes, improvements can be identified, but large remaining systematic biases can still be found.

\subsection{Common mode correction}

In the previous section, it is shown that our soft calibration effectively eliminates systematic biases of measurements relative to VLIDORT simulations for most cases, except for high latitudes/SZAs where there still exists a distinct wavelengthdependent pattern in fitting residuals, because the soft calibration spectrum is derived only under small SZA conditions. In order to verify and correct such systematic biases that remain after soft calibration, we characterize spectral fitting residuals at the final iteration classified into three lati- 
(a)

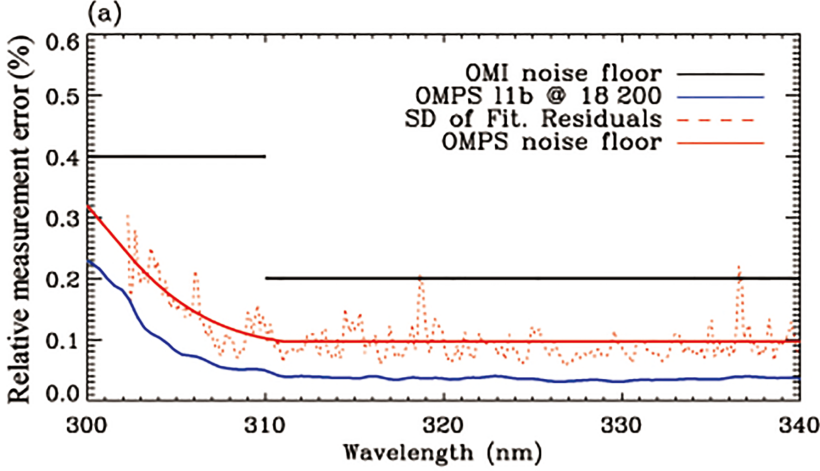

(b)

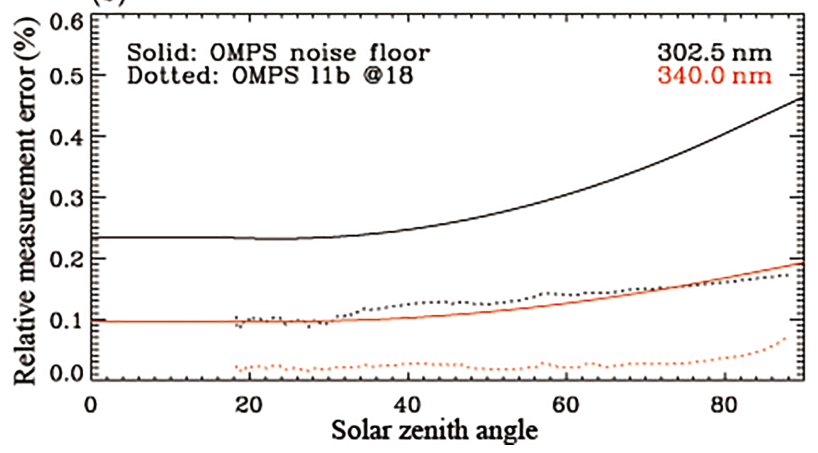

Figure 12. (a) Standard deviations of spectral fitting residuals for 14 March 2013 under clear-sky conditions and for small SZAs $<40^{\circ}$ (red dotted line), with the fourth-order polynomial fitting (red solid line) called "OMPS noise floor (NF) error". This NF error represents the minimum measurement constraint implemented in OMPS ozone fitting process. OMI floor noise error (black line) and OMPS L1B v2.0 random-noise error (blue line; orbit: 7132, cross-track: 18, along-track: 200) are also shown for comparison in the same panel. (b) OMPS NF at 302.5 and $340 \mathrm{~nm}$ as a function of SZAs (solid line), with the corresponding OMPS L1B v2.0 measurement error (dotted line).

tude/SZA regimes (southern polar region/SZA $>60^{\circ}$, tropical region $/ \mathrm{SZA}<40^{\circ}$, northern polar region $/ \mathrm{SZA}>60^{\circ}$ ) for each cross-track position and for 1 day (14th or 15th) of each month. The remainder is called the common residual spectrum. Examples of derived common spectra are presented in Fig. 9 for March and August 2013. The main peak positions of residuals of all common residual spectra are well matched. The amplitude of the tropical residuals is very similar for the 2 months, whereas the variation of the amplitude at high latitudes seems to be associated with snow/ice cover and SZA variations such that the amplitude is maximized during the polar winter season. Applying the common mode correction (CMC) means subtracting the common spectrum with amplitude determined iteratively along with the rest of state vector components from the measured spectrum. Figure $10 \mathrm{com}-$ pares the fitting residuals at high SZAs for one orbit of data on 2 March 2013 with and without the common mode correction. It is evident that wavelength-dependent fitting residuals are greatly reduced, even for the first few wavelengths with amplitude of spectral residuals reduced from $\sim 1$ to $0.5 \%$. Moreover, the common mode correction slightly reduces the standard deviations of residuals. The improvement is seen everywhere as shown in Fig. 11 where rms of relative fitting residuals (ratio of fitting residuals to measurements error) is displayed for all individual pixels within one orbit.

\subsection{Measurement error correction}

The measurement error covariance matrix $\mathbf{S}_{y}$ is one of the essential inputs in an OE-based algorithm, because it significantly affects the stability of retrievals and retrieval sensitivities. OMPS L1B v2.0 data contain the relative errors of radiance measurements, but these measurement errors $(\sim 0.04 \%$ at $320 \mathrm{~nm}$ ) were too small to regularize our ozone fitting process, so many retrievals fail due to negative or large positive ozone values as a result of over fitting. Ideally, the measurement errors need to include not only photon shot noise but also other kinds of random noise errors caused by readout, stray light, dark current, geophysical pseudo-random noise errors due to subpixel variability and motion when taking measurements, forward model parameter errors (random part) and other unknown errors. However, OMPS measurement errors reported in the L1B only include photon shot noise and read-out errors, which underestimate the overall measurement error. For this reason, OMI noise floor (NF) errors instead of OMPS random-noise errors are imposed on our preliminary retrievals, as mentioned in Sect 2.3. However, better signal-to-noise ratios (SNRs) could be expected for OMPS than OMI due to OMPS's coarser spectral and spatial resolutions, as shown from the improved detection limit of OMPS $\mathrm{H}_{2} \mathrm{CO}$ retrievals compared to OMI as discussed in Gonzalez Abad et al. (2016). Figure 11 also implies that there is room for increasing the degrees of freedom for signal (DFS) to current ozone retrievals by regularizing them using the improved measurement error instead of using OMI NF; the ideal value of rms is one, but our rms is mostly within 0.4 at low and middle latitudes. The random-noise component of measurements could be derived from standard deviations of spectral fitting residuals (Cai et al., 2012; Liu et al. 2015b). Figure 12 shows how we derive the measurement errors to improve our retrievals. We first characterize the minimum measurement errors from fitting residuals under near-clear-sky conditions at SZAs $<40^{\circ}$ and cross-track pixels between 4 and 33; note that no radiometric calibration is applied to these fitting residuals. The standard deviations of fitting residuals are nearly invariant at longer wavelengths $>310 \mathrm{~nm}$ and show a significant increase from $\sim 0.1 \%$ at $310 \mathrm{~nm}$ to $\sim 0.3 \%$ at $302 \mathrm{~nm}$, plotted with the red dashed line in Fig. 12a. We eliminate the low-frequency portion of the noises with a four-order polynomial fit to define the minimum OMPS NF errors, plotted with the red solid line in Fig. 12a. The derived NF errors are $\sim 2(1.5-4)$ times smaller than OMI NF errors above (below) $310 \mathrm{~nm}$ and thereby could increase the measurement information in our retrievals. We 

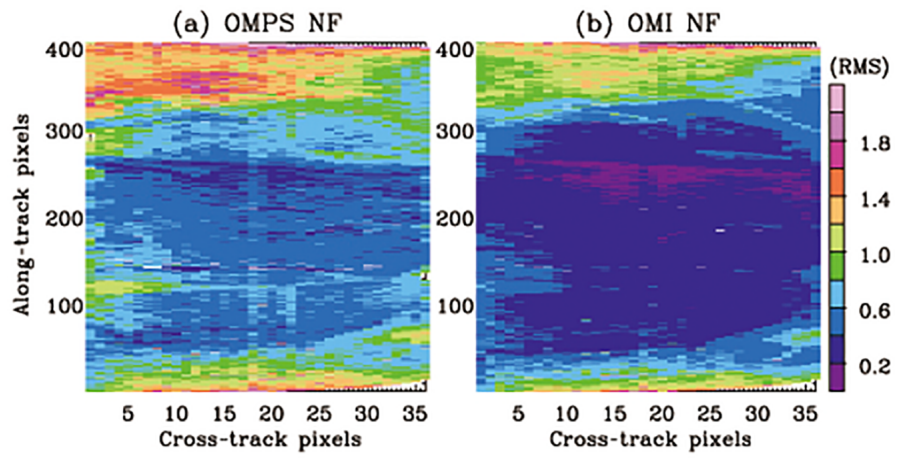

(c) OMPS NF - OMI NF
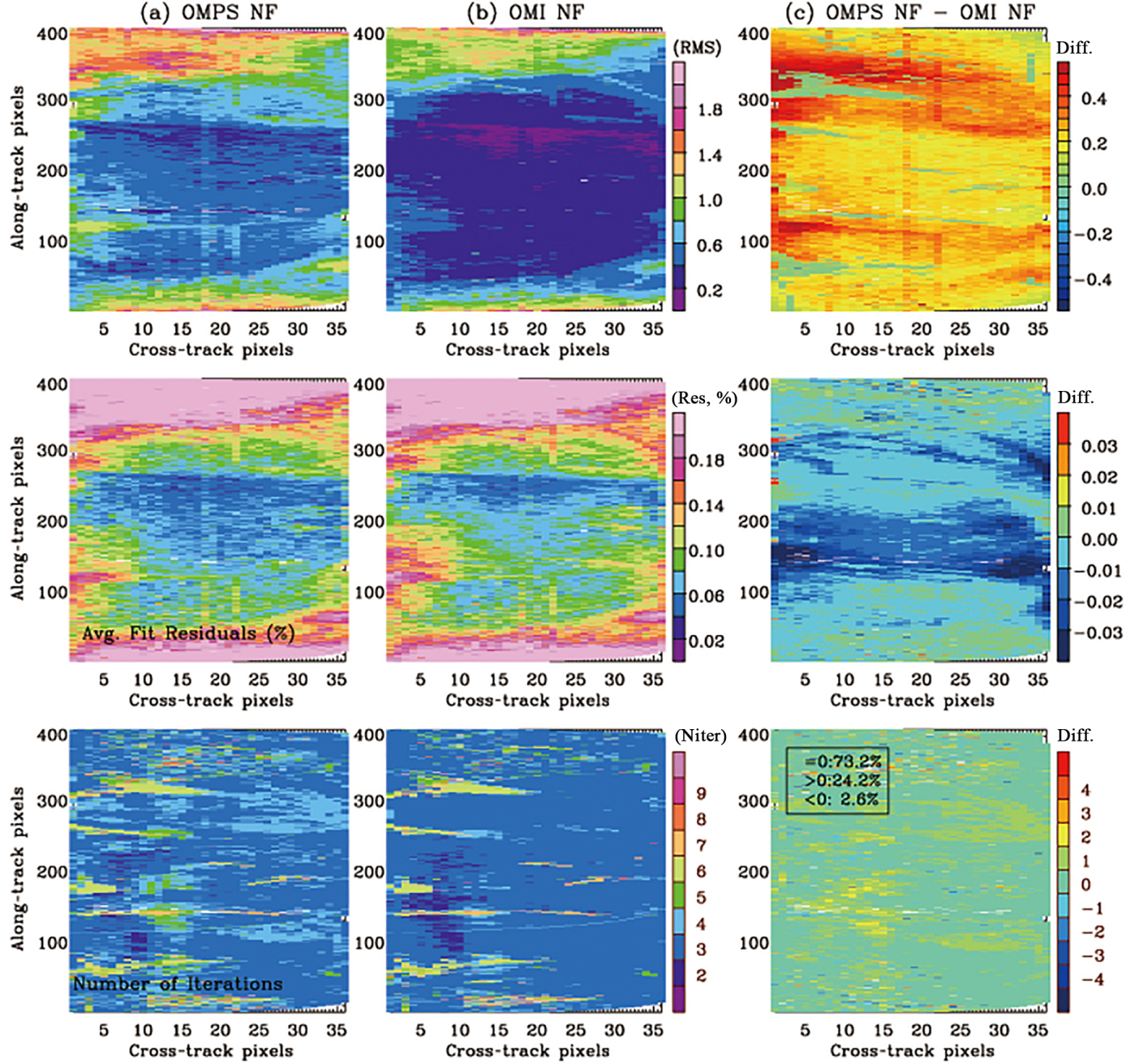

Cross-track pixels

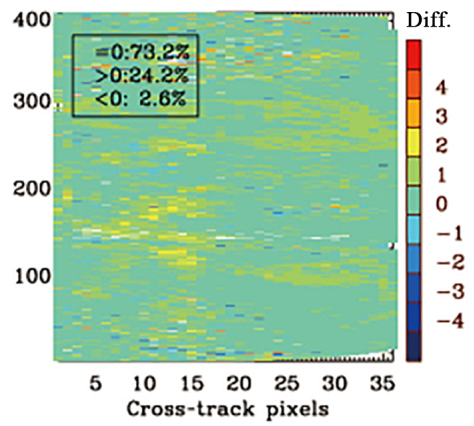

Figure 13. Top: comparison of rms of fitting residuals relative to the assumed measurement errors as functions of cross-track and along-track pixels for orbit 7132 with (a) OMPS NF (first column) and (b) OMI NF (second column), respectively, with (c) their absolute differences (third column). The definition of rms is given in Fig. 11. Middle: comparison of average fitting residuals relative to the simulated radiances (\%), which are similar to rms, except that radiance differences are normalized to measured radiances instead of measurement errors. Bottom: comparison of the number of the retrieval iterations.

impose the minimum NF errors as a measurement constraint in our algorithm when SZAs are smaller than $\sim 20^{\circ}$, whereas they are multiplied by a SNR scaling factor to increase measurement errors as a function of SZAs. Figure $12 \mathrm{~b}$ shows an example of how derived measurement errors increase with SZA at the boundary wavelengths of the ozone fitting window, with errors from 0.24 to $0.45 \%$ for $302.5 \mathrm{~nm}$ and from 0.097 to $0.19 \%$ for $340 \mathrm{~nm}$.

Figure 13 shows the effect of using the derived NF errors on our retrievals. The rms of fitting residuals increases from $0.2-0.4$ to $0.4-0.8$ in swath lines $50-350$, where SZAs are within $\sim 60^{\circ}$ due to SNR increases, whereas the average fitting residuals slightly improve by $0.015 \%$. Using the new NF errors slightly increases the number of iterations; one or more iterations are required for $\sim 24 \%$ of the total re- trieved pixels and hence our fitting process converges mostly within 3-4 times, except for thick clouds, where the number of iterations increases to 6 . Using the derived NF errors significantly increases the retrieval information content. Both stratospheric and tropospheric DFSs are improved by $0.2-0.4$ under mild SZAs and by up to 0.2 under high SZAs as shown in Fig. 14, so that tropospheric ozone retrievals demonstrate $\sim 1$ DFS in low and middle latitudes, which is similar to OMI retrievals (Liu et al., 2010). Figure 15a shows the retrieved tropospheric ozone column distribution with two radiometric calibrations (soft, CMC) and OMPS NF errors. Compared to Fig. 7b without CMC and OMI NF errors, the cross-trackdependent noises over the polar region are smoothed due to CMC and the columns are enhanced in the tropics and the northern midlatitudes due to OMPS NF errors. Successful 
(a) OMPS NF
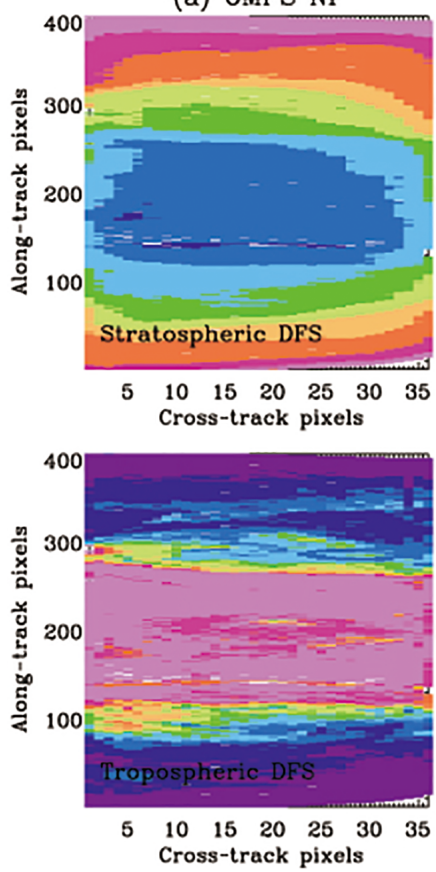

(b) OMI NF

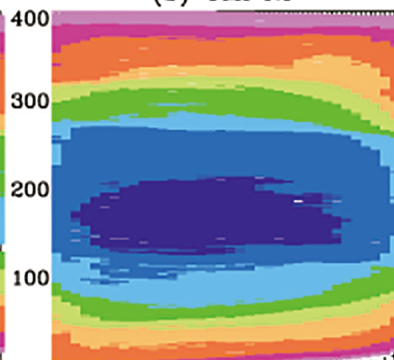

$\begin{array}{lllllll}5 & 10 & 15 & 20 & 25 & 30 & 35\end{array}$ Cross-track pixels

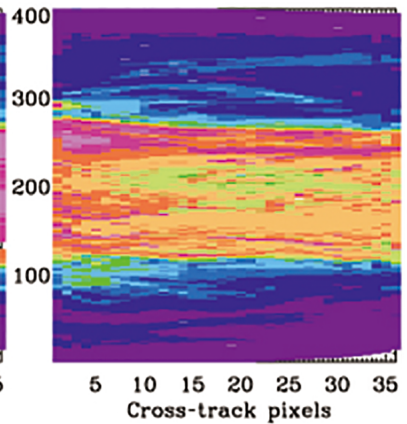

(c) OMPS NF - OMI NF
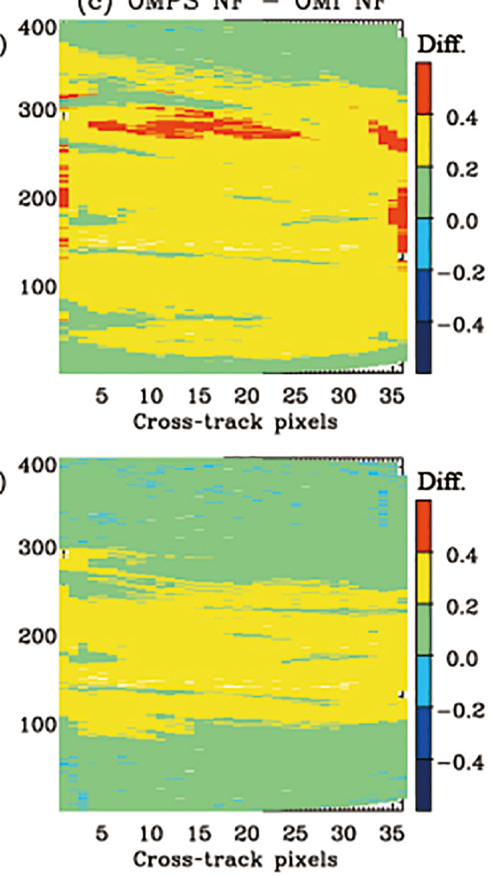

Figure 14. Same as Fig. 13 but for the integrated degrees of freedom for signal (DFS) in the stratosphere (top) and troposphere (bottom).

(a) Tropospheric column ozone

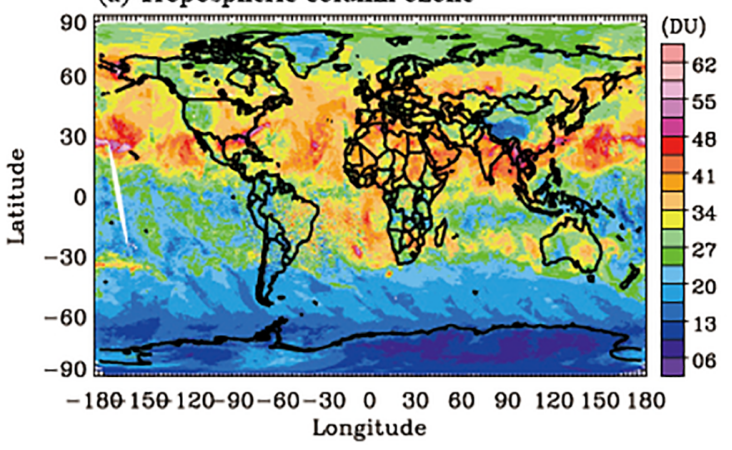

(b) Avg. fitting residuals

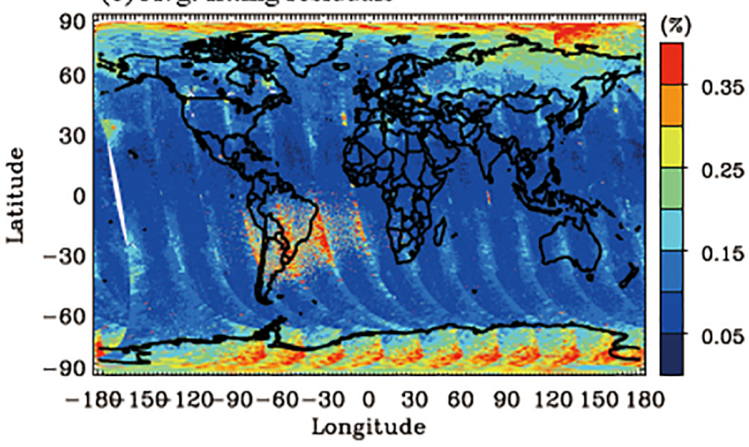

Figure 15. (a) Same as Fig. 7b but for improved retrievals with common mode correction and OMPS noise floor error, (b) corresponding average fitting residuals $(\%)$.

tropospheric retrievals typically require fitting accuracy better than $0.2-0.3 \%$ between measured and modeled radiances in the Huggins band (310-340 nm; Munro et al., 1998). Our fitting algorithm meets this requirement after empirical calibrations are carefully applied as shown in Fig. 15b; the average fitting residuals are within $0.1 \%$ for moderate SZAs, with insignificant dependence on cross-track position.

\section{Conclusions}

The OMI ozone profile algorithm has been adapted and modified to retrieve tropospheric ozone and ozone profiles from the OMPS-NM L1B 2.0 product. To verify the best knowledge of OMPS instrument slit functions, we evaluate
OMPS preflight-measured slit functions and analytical slit functions assuming standard and super Gaussian distributions through cross-correlation using a high-resolution solar reference spectrum. We also adjust preflight-measured slit functions to post-launch OMPS measurements by broadening/squeezing them by up to $4 \%$, which slightly improves the fitting residuals at nadir cross-track pixels but by up to $0.18 \%$ (e.g., from 0.75 to $0.6 \%$ at the first cross-track position) at edge pixels. The super Gaussian slit functions represent OMPS irradiances better than the standard Gaussian and even better than the preflight-measured slit functions, but the fitting residuals of radiances with different slit functions show insignificant differences. OMPS-measured slit functions are finally implemented in our OMPS ozone fitting re- 
trievals, because they take into account the slight dependence of slit functions on wavelengths.

We perform two kinds of radiometric calibrations to eliminate the systematic components of fitting residuals. First, we apply "soft calibration" to OMPS radiance before retrievals. This correction spectrum is derived as a function of wavelength and cross-track position by averaging the ratio of measured radiances to simulated radiances using collocated OMI ozone profile retrievals in the tropics under near-clearsky conditions for 25 days of May 2013. Applying soft calibration to OMPS radiance dramatically improves the spectral fitting residuals, especially under low to moderate SZA. The amplitude of fitting residuals decreases from 1 to $0.2 \%$. Therefore, the significant cross-track striping pattern shown in preliminary OMPS tropospheric ozone retrievals is mostly eliminated. Second, the CMC is implemented to compensate fitting residuals uncorrected by soft calibration, especially for high SZA retrievals. This correction spectrum is derived as functions of wavelength and cross-track position by averaging 1 day's fitting residuals over the tropics and northern and southern high latitude regions, respectively. The amplitude of the correction spectrum is iteratively and simultaneously adjusted with ozone. It is found that the amplitude of the fitting residuals decreases by a factor of 2 due to the CMC over high latitudes.

Our preliminary algorithm uses OMI NF errors to represent measurement constraints, because OMPS L1B randomnoise errors are too tight to stabilize retrievals. However, we found that OMI NF errors cannot sufficiently constrain our OMPS retrievals, indicating that there is room to increase the retrieval sensitivity to measurement information by improving measurement constraints. Therefore, we derive the minimum NF error corresponding to standard deviations of spectral fitting residuals over the tropics. The derived minimum NF error is $\sim 0.097 \%$ in $310-340 \mathrm{~nm}$ and increases to $\sim 0.24 \%$ at $302.5 \mathrm{~nm}$, which is smaller than the OMI error by a factor of $1.5-4$ below $310 \mathrm{~nm}$ and 2 above. We apply this minimum NF error to SZAs $<\sim 20^{\circ}$ and those multiplied by a SNR scaling factor to take into account the decreasing SNR with increasing SZA at SZAs $>\sim 20^{\circ}$; when SZA is $90^{\circ}$ errors increase to $0.45 \%$ at $302.5 \mathrm{~nm}$ and $0.19 \%$ at $340 \mathrm{~nm}$. Using OMPS NF errors as a retrieval constraint slightly improves the fitting residuals, by $0.015 \%$ on average, and both stratospheric and tropospheric ozone retrieval sensitivity (DFS increases by $0.2-0.4$ ) but requires 1 or more additional iterations for convergence. In this study, we meet the requirement to achieve successful tropospheric ozone retrievals in terms of DFS $(>1)$ and fitting residuals $(<0.2-$ $0.3 \%$ ) with empirical calibrations optimized to OMPS L1B measurements. In future work, we will characterize OMPS ozone profile retrievals, present error analysis and validate retrievals using a reference data set to verify that the quality of OMPS ozone retrievals is adequate for scientific use.
Data availability. The data used or produced in this study are available upon request from the corresponding author or the first author. OMPS L1B v2.0 data are publicly available at the website https://ozoneaq.gsfc.nasa.gov/omps/ and OMPS L2 cloud data upon request from Alexander Vasilkov (alexander.vasilkov@ssaihq.com)

Competing interests. The authors declare that they have no conflict of interest.

Acknowledgements. We acknowledge the OMI and OMPS science teams for providing their satellite data and Glen Jaross for providing useful comments regarding OMPS level 1B v2.0 data. We thank Alexander Vasilkov for allowing the OMPS cloud product to be used in this study. Research at Pusan National University by Juseon Bak was financially supported by the 2016 Post-Doc. Development Program of Pusan National University. Jae Hwan Kim was supported by ETRI, which is a subproject of the Development of Geostationary Meteorological Satellite Ground Segment (NMSC-2017-01) program funded by the NMSC (National Meteorological Satellite Center) of KMA (Korea Meteorological Administration). Research at the Smithsonian Astrophysical Observatory by Xiong Liu, Kelly Chance and Kang Sun was funded by NASA Aura science team program (NNX14AF16G) and the Smithsonian Institution. Kai Yang was funded by NASA Suomi NPP science team program (NNX14AR20A).

Edited by: Helen Worden

Reviewed by: Glen Jaross and one anonymous referee

\section{References}

Bak, J., Kim, J. H., Liu, X., Chance, K., and Kim, J.: Evaluation of ozone profile and tropospheric ozone retrievals from GEMS and OMI spectra, Atmos. Meas. Tech., 6, 239-249, https://doi.org/10.5194/amt-6-239-2013, 2013a.

Bak, J., Libaku, X., Wei, J. C., Pan, L. L., Chance, K., and Kim, J. H.: Improvement of OMI ozone profile retrievals in the upper troposphere and lower stratosphere by the use of a tropopausebased ozone profile climatology, Atmos. Meas. Tech., 6, 22392254, https://doi.org/10.5194/amt-6-2239-2013, 2013b.

Bak, J., Liu, X., Kim, J. H., Chance, K., and Haffner, D. P.: Validation of OMI total ozone retrievals from the SAO ozone profile algorithm and three operational algorithms with Brewer measurements, Atmos. Chem. Phys., 15, 667-683, https://doi.org/10.5194/acp-15-667-2015, 2015.

Beirle, S., Lampel, J., Lerot, C., Sihler, H., and Wagner, T.: Parameterizing the instrumental spectral response function and its changes by a super-Gaussian and its derivatives, Atmos. Meas. Tech., 10, 581-598, https://doi.org/10.5194/amt-10-5812017, 2017.

Bhartia, P. K. and Wellemeyer, C.: TOMS-V8 total O3 algorithm, in: OMI Algorithm Theoretical Basis Document, Vol. II, OMI Ozone Products, edited by: Bhartia, P. K., NASA Goddard Space Flight Cent., Greenbelt, MD, 15-31, 2002.

Bhartia, P. K., McPeters, R. D., Flynn, L. E., Taylor, S., Kramarova, N. A., Frith, S., Fisher, B., and DeLand, M.: Solar Backscatter 
UV (SBUV) total ozone and profile algorithm, Atmos. Meas. Tech., 6, 2533-2548, https://doi.org/10.5194/amt-6-2533-2013, 2013.

Bovensmann, H., Burrows, J. P., Buchwitz, M., Frerick, J., Noel, S., Rozanov, V. V., Chance, K. V., and Goede, A. P. H.: SCIAMACHY: Mission objectives and measurement modes, J. Atmos. Sci., 56, 127-150, https://doi.org/10.1175/15200469(1999)056<0127:SMOAMM>2.0.CO;2, 1999.

Brion, J., Chakir, A., Daumont, D., and Malicet, J.: High-resolution laboratory absorption cross section of O3. Temperature effect, Chem. Phys. Lett., 213, 610-612, 1993.

Cai, Z., Liu, Y., Liu, X., Chance, K., Nowlan, C. R., Lang, R., Munro, R., and Suleiman, R.: Characterization and correction of Global Ozone Monitoring Experiment 2 ultraviolet measurements and application to ozone profile retrievals, J. Geophys. Res., 117, D07305, https://doi.org/10.1029/2011JD017096, 2012.

Caspar, C. and Chance, K.: GOME wavelength calibration using solar and atmospheric spectra, Third ERS Symposium on Space at the Service of our Environment, Florence, Italy, 14-21 March, 1997.

Chance, K. and Kurucz, R. L.: An improved high-resolution solar reference spectrum for earth's atmosphere measurements in the ultraviolet, visible, and near infrared, J. Quant. Spectrosc. Ra., 111, 1289-1295, https://doi.org/10.1016/j.jqsrt.2010.01.036, 2010.

Chance, K., Liu, X., Suleiman, R. M., Flittner, D. E., AlSaadi, J., and Janz, S. J.: Tropospheric emissions: monitoring of pollution (TEMPO), Proc. SPIE 8866, Earth Observing Systems XVIII, 8866, 88660D-1-88660D-16, https://doi.org/10.1117/12.2024479, 2013.

Dirksen, R., Dobber, M., Voors, R., and Levelt, P.: Prelaunch characterization of the Ozone Monitoring Instrument transfer function in the spectral domain, Appl. Opt., 45, 3972-3981, https://doi.org/10.1364/ao.45.003972, 2006.

European Space Agency: The GOME Users Manual, ESA Publ. SP1182, Publ. Div., Eur. 488 Space Res. and Technol. Cent., Noordwijk,the Netherlands, 1995.

European Organisation for the Exploitation of Meteorological Satellites (EUMETSAT): GOME-2 level 1 Product Generation Specification, Rep. EPS.SYS.SPE.990011, Darmstadt, Germany, 2006.

Flynn, L., Long, C., Wu, X., Evans, R., Beck, C. T., Petropavlovskikh, I., McConville, G., Yu, W., Zhang, Z., Niu, J., Beach, E., Hao, Y., Pan, C., Sen, B., Novicki, M., Zhou, S., and Seftor, C. : Performance of the Ozone Mapping and Profiler Suite (OMPS) products, J. Geophys. Res.-Atmos., 119, 61816195, https://doi.org/10.1002/2013JD020467, 2014.

González Abad, G., Vasilkov, A., Seftor, C., Liu, X., and Chance, K.: Smithsonian Astrophysical Observatory Ozone Mapping and Profiler Suite (SAO OMPS) formaldehyde retrieval, Atmos. Meas. Tech., 9, 2797-2812, https://doi.org/10.5194/amt-9-27972016, 2016.

Hörmann, C., Sihler, H., Beirle, S., Penning de Vries, M., Platt, U., and Wagner, T.: Seasonal variation of tropospheric bromine monoxide over the Rann of Kutch salt marsh seen from space, Atmos. Chem. Phys., 16, 13015-13034, https://doi.org/10.5194/acp-16-13015-2016, 2016.
Huang, G., Liu, X., Chance, K., Yang, K., Bhartia, P. K., Cai, Z., Allaart, M., Ancellet, G., Calpini, B., Coetzee, G. J. R., CuevasAgulló, E., Cupeiro, M., De Backer, H., Dubey, M. K., Fuelberg, H. E., Fujiwara, M., Godin-Beekmann, S., Hall, T. J., Johnson, B., Joseph, E., Kivi, R., Kois, B., Komala, N., König-Langlo, G., Laneve, G., Leblanc, T., Marchand, M., Minschwaner, K. R., Morris, G., Newchurch, M. J., Ogino, S.-Y., Ohkawara, N., Piters, A. J. M., Posny, F., Querel, R., Scheele, R., Schmidlin, F. J., Schnell, R. C., Schrems, O., Selkirk, H., Shiotani, M., Skrivánková, P., Stübi, R., Taha, G., Tarasick, D. W., Thompson, A. M., Thouret, V., Tully, M. B., Van Malderen, R., Vömel, H., von der Gathen, P., Witte, J. C., and Yela, M.: Validation of 10-year SAO OMI Ozone Profile (PROFOZ) product using ozonesonde observations, Atmos. Meas. Tech., 10, 2455-2475, https://doi.org/10.5194/amt-10-2455-2017, 2017a.

Huang, G., Liu, X., Chance, K., Yang, K., and Cai, Z.: Validation of 10-year SAO OMI Ozone Profile (PROFOZ) Product Using Aura MLS Measurements, Atmos. Meas. Tech. Discuss., https://doi.org/10.5194/amt-2017-92, in review, 2017b.

Jaross, G.: OMPS/NPP L1B NM Radiance EV Calibrated Geolocated Swath Orbital V2, Goddard Earth Sciences Data and Information Services Center (GES DISC), Greenbelt, MD, USA, https://doi.org/10.5067/DL081SQY7C89, 2017

Kleipool, Q. L., Dobber, M. R., de Haan, J. F., and Levelt, P. F.: Earth surface reflectance climatology from 3 years of OMI data, J. Geophys. Res., 113, D18308, https://doi.org/10.1029/2008JD010290, 2008.

Kroon, M., de Haan, J. F., Veefkind, J. P., Froidevaux, L., Wang, R., Kivi, R., and Hakkarainen, J. J.: Validation of operational ozone profiles from the Ozone Monitoring Instrument, J. Geophys Res., 116, D18305, https://doi.org/10.1029/2010JD015100, 2011.

Kurosu, T. P., Chance, K., and Sioris, C. E.: Preliminary results for $\mathrm{HCHO}$ and $\mathrm{BrO}$ from the EOS-Aura Ozone Monitoring Instrument, in Passive Optical Remote Sensing of the Atmosphere and Clouds IV, Proc. of SPIE Vol. 5652, https://doi.org/10.1117/12.578606, 2004.

Levelt, P. F., van den Oord, G. H. J., Dobber, M. R., Malkki, A., Visser, H., de Vries, J., Stammes, P., Lundell, J. O. V., and Saari, H.: The Ozone Monitoring Instrument, IEEE T. Geosci. Remote, 44, 1093-1101, https://doi.org/10.1109/TGRS.2006.872333, 2006.

Liu, C., Liu, X., Kowalewski, M. G., Janz, S. J., González Abad, G., Pickering, K. E., Chance, K., and Lamsal, L. N.: Characterization and verification of ACAM slit functions for tracegas retrievals during the 2011 DISCOVER-AQ flight campaign, Atmos. Meas. Tech., 8, 751-759, https://doi.org/10.5194/amt-8751-2015, 2015a.

Liu, C., Liu, X., Kowalewski, M. G., Janz, S. J., González Abad, G., Pickering, K. E., Chance, K., and Lamsal, L. N.: Analysis of ACAM Data for Trace Gas Retrievals during the 2011 DISCOVER-AQ Campaign, J. Spectroscopy, ID827160, https://doi.org/10.1155/2015/827160, 2015b.

Liu, X., Chance, K., Sioris, C. E., Spurr, R. J. D., Kurosu, T. P., Martin, R. V., and Newchurch, M. J.: Ozone profile and tropospheric ozone retrievals from Global Ozone Monitoring Experiment: algorithm description and validation, J. Geophys. Res. 110, D20307, https://doi.org/10.1029/2005JD006240, 2005. 
Liu, X., Bhartia, P. K., Chance, K., Spurr, R. J. D., and Kurosu, T. P.: Ozone profile retrievals from the Ozone Monitoring Instrument, Atmos. Chem. Phys., 10, 2521-2537, https://doi.org/10.5194/acp-10-2521-2010, 2010.

Munro, R., Siddans, R., Reburn, W. J., and Kerridge, B.: Direct measurement of tropospheric ozone from space, Nature, 392, 168-171, 1998.

Munro, R., Lang, R., Klaes, D., Poli, G., Retscher, C., Lindstrot, R., Huckle, R., Lacan, A., Grzegorski, M., Holdak, A., Kokhanovsky, A., Livschitz, J., and Eisinger, M.: The GOME-2 instrument on the MetOp series of satellites: instrument design, calibration, and level 1 data processing - an overview, Atmos. Meas. Tech., 9, 1279-1301, https://doi.org/10.5194/amt-9-12792016, 2016.

Nowlan, C. R., Liu, X., Chance, K., Cai, Z., Kurosu, T. P., Lee, C., and Martin, R. V.: Retrievals of sulfur dioxide from the global ozone monitoring experiment 2 (GOME2) using an optimal estimation approach: algorithm and initial validation, J. Geophys. Res.-Atmos., 116, D18301, https://doi.org/10.1029/2011JD015808, 2011.

Nowlan, C. R., Liu, X., Leitch, J. W., Chance, K., González Abad, G., Liu, C., Zoogman, P., Cole, J., Delker, T., Good, W., Murcray, F., Ruppert, L., Soo, D., Follette-Cook, M. B., Janz, S. J., Kowalewski, M. G., Loughner, C. P., Pickering, K. E., Herman, J. R., Beaver, M. R., Long, R. W., Szykman, J. J., Judd, L. M., Kelley, P., Luke, W. T., Ren, X., and AlSaadi, J. A.: Nitrogen dioxide observations from the Geostationary Trace gas and Aerosol Sensor Optimization (GeoTASO) airborne instrument: Retrieval algorithm and measurements during DISCOVER-AQ Texas 2013, Atmos. Meas. Tech., 9, 26472668, https://doi.org/10.5194/amt-9-2647-2016, 2016.

Rodgers, C. D.: Inverse Methods for Atmospheric Sounding: Theory and Practice, World Scientific Publishing, Singapore, 2000.

Pittman, J. V., Pan, L. L., Wei, J. C., Irion, F. W., Liu, X., Maddy, E. S., Barnet, C. D., Chance, K., and Gao, R.-S.: Evaluation of AIRS, IASI, and OMI ozone profile retrievals in the extratropical tropopause region using in situ aircraft measurements, J. Geophys. Res., 114, D24109, https://doi.org/10.1029/2009JD012493, 2009.

Schenkeveld, V. M. E., Jaross, G., Marchenko, S., Haffner, D., Kleipool, Q. L., Rozemeijer, N. C., Veefkind, J. P., and Levelt, P. F.: In-flight performance of the Ozone Monitoring Instrument, Atmos. Meas. Tech., 10, 1957-1986, https://doi.org/10.5194/amt-10-1957-2017, 2017.

Seftor, C. J. and Jaross, G.: NMEV-L1B Data Release Notes, available at: https://ozoneaq.gsfc.nasa.gov/omps/media/docs/ NMEV-L1B_Release_Notes.pdf, last access: 20 July 2017.

Seftor, C. J., Jaross, G., Kowitt, M., Haken, M., Li, J., and Flynn, L. E.: Postlaunch performance of the Suomi National Polar orbiting Partnership Ozone Mapping and Profiler Suite (OMPS) nadir sensors, J. Geophys. Res.-Atmos., 119, 44134428, https://doi.org/10.1002/2013JD020472, 2014.
Sioris, C. E. and Evans, W. F. J.: Impact of rotational Raman scattering in the O2 A band, Geophys. Res. Lett., 27, 4085-4088, 2000.

Spurr, R. J.: VLIDORT: A linearized pseudo-spherical vector discrete ordinate radiative transfer code for forward model and retrieval studies in multilayer multiple scattering media, J. Quant. Spectrosc. Ra., 102, 316-342, https://doi.org/10.1016/j.jqsrt.2006.05.005, 2006.

Spurr, R. J. D.: Linearized pseudo-spherical scalar and vector discrete ordinate radiative transfer models for use in remote sensing retrieval problems, in: Light Scattering Reviews, edited by: Kokhanovsky, A., Springer, New York, 2008.

Sun, K., Liu, X., Nowlan, C. R., Cai, Z., Chance, K., Frankenberg, C., Lee, R. A. M., Pollock, R., Rosenberg, R., and Crisp, D.: Characterization of the OCO-2 instrument line shape functions using on-orbit solar measurements, Atmos. Meas. Tech. 10, 939-953, https://doi.org/10.5194/amt-10-939-2017, 2017 a.

Sun, K., Liu, X., Huang, G., González Abad, G., Cai, Z., Chance, K., and Yang, K.: Deriving the slit functions from OMI solar observations and its implications for ozone-profile retrieval, Atmos. Meas. Tech., 10, 3677-3695, https://doi.org/10.5194/amt10-3677-2017, 2017b.

Vasilkov, A., Joiner, J., and Seftor, C.: First results from a rotational Raman scattering cloud algorithm applied to the Suomi National Polar-orbiting Partnership (NPP) Ozone Mapping and Profiler Suite (OMPS) Nadir Mapper, Atmos. Meas. Tech., 7, 2897-2906, https://doi.org/10.5194/amt-7-2897-2014, 2014.

Veefkind, J. P., Aben, I., McMullan, K., Förster, H., de Vries, J., Otter, G., Claas, J., Eskes, H. J., de Haan, J. F., Kleipool, Q., van Weele, M., Hasekamp, O., Hoogeveen, R., Landgraf, J., Snel, R., Tol, P., Ingmann, P., Voors, R., Kruizinga, B., Vink, R., Visser, H., and Levelt, P. F.: TROPOMI on the ESA Sentinel-5 Precursor: A GMES mission for global observations of the atmospheric composition for climate, air quality and ozone layer applications, Remote Sens. Environ., 120, 70-83, https://doi.org/10.1016/j.rse.2011.09.027, 2012.

Yang, K., Dickerson, R. R., Carn, S. A., Ge, C., and Wang, J.: First observations of $\mathrm{SO}_{2}$ from the satellite Suomi NPP OMPS: Widespread air pollution events over China, GRL, https://doi.org/10.1002/grl.50952, 2013.

Yang, K., Carn, S. A., Ge, C., Wang, J., and Dickerson, R. R. : Advancing measurements of tropospheric $\mathrm{NO}_{2}$ from space: New algorithm and first global results from OMPS, Geophys. Res. Lett., 41, 4777-4786, https://doi.org/10.1002/2014GL060136, 2014.

Zoogman, P., Liu, X., Suleiman, R. M., et al.: Tropospheric Emission: Monitoring of Pollution (TEMPO), J. Quant. Spectrosc. Ra., 186, 17-39, https://doi.org/10.1016/j.jqsrt.2016.05.008, 2017. 